\title{
Active control of boundary lubrication of ceramic tribo-pairs in sodium dodecyl sulfate aqueous solutions
}

Yonggang Meng ( $\nabla$ mengyg@tsinghua.edu.cn )

Tsinghua University https://orcid.org/0000-0002-8274-5131

Chenxu Liu

Tsinghua University School of Mechanical Engineering

Jingbo Fang

Tsinghua University School of Mechanical Engineering

\section{Xiangli Wen}

Tsinghua University School of Mechanical Engineering

\section{Yu Tian}

Tsinghua University School of Mechanical Engineering

\section{Research Article}

Keywords: water-based lubrication, surfactant, ceramics, boundary lubrication, potential-control

Posted Date: April 28th, 2021

DOI: https://doi.org/10.21203/rs.3.rs-364775/v1

License: (9) This work is licensed under a Creative Commons Attribution 4.0 International License. Read Full License 


\title{
Active control of boundary lubrication of ceramic tribo-pairs in sodium dodecyl sulfate aqueous solutions
}

\author{
Chenxu Liu, Jingbo Fang, Xiangli Wen, Yu Tian, Yonggang Meng* \\ State Key Laboratory of Tribology, Tsinghua University, Beijing 100084, \\ China \\ *Corresponding author: mengyg@tsinghua.edu.cn
}

\begin{abstract}
The objective of the study is to actively control friction between engineering ceramics in underwater applications. By designing a proper electrode system and applying an external electric field, the active control of friction between $\mathrm{Al}_{2} \mathrm{O}_{3}$ plate and $\mathrm{ZrO}_{2}$ ball in sodium dodecyl sulfate (SDS) aqueous solutions has been realized, which is different from the previous studies of potential controlled boundary lubrication where at least one part of tribo-pairs is a conductor. Reversible change of friction coefficient has been observed in the range from 0.12 to 0.35 . An indirect electric field-assisted adsorption model has been proposed to explain the observed phenomena. The addition of inorganic salts containing counterions to the SDS solution or increasing the concentration of SDS can shorten the response time of friction to the variation of the applied electric field by facilitating the formation of SDS micelles. This opens a new way to realize the active control of friction for insulative tribo-pairs without corrosion. Keywords: water-based lubrication, surfactant, ceramics, boundary lubrication, potential-control
\end{abstract}




\section{Introduction}

Since 1980's, engineering ceramics have been increasingly employed for structures and components of machine systems because of their excellent properties such as high corrosion resistance, high wear resistance, high melting point and low density.[1] Oxides, nitrides and carbides ceramics including $\mathrm{A}_{2}{ }_{2} \mathrm{O}_{3}, \mathrm{ZrO}_{2}, \mathrm{Si}_{3} \mathrm{~N}_{4}$ and SiC offer many possibilities of producing components with beneficial combinations of properties with good tribological performance[2].

Recently, researches on tribology of ceramic/metal and ceramic/ceramic pairs in sliding contact becomes important for a lot of engineering applications, including roller bearings, journal bearings, seal rings, valves, artificial joints and parts for internal combustion engines[3]. For example, Aronov and Mesyef[4] investigated wear mechanisms in sliding contact of partially stabilized zirconia rubbed against itself and against different kinds of steels at high temperatures and exhaust gas environment in combustion systems. Johannes and his co-workers[5] found that advanced ceramics show potentials to increase heat transfer and improve power density of lubricated clutch systems. Moreover, some previous studies also showed that ceramic/metal and ceramic/ceramic tribo-pairs own superiority in some aspects over metallic materials. Cilingir and his co-workers[6] used the finite element method to investigate the contact mechanics and stress/strain distributions of hip resurfacing for different bearing couples, and they found that ceramic-ceramic or ceramic-metal bearing couples could reduce osteolysis as well as adhesive wear. They concluded that ceramics-on-metal friction pairs would be better design for hip resurfacing 
arthroplasty, avoiding the problem of stem fracture risk of femoral component. Yamamoto and his co-workers[7] focused on rolling life of ceramic bearings in water and found that all ceramic $\left(\mathrm{Si}_{3} \mathrm{~N}_{4}, \mathrm{ZrO}_{2}, \mathrm{SiC}\right)$ bearings possess 15-70 times longer rolling fatigue life than all AISI440C steel bearings, and thus could be especially applicable to corrosive environment in various cleaning equipment for manufacturing semiconductors and liquid crystal display panels, food processing machinery, chemical plants, etching equipment and so on.

Another advantage of the ceramic/metal and ceramic/ceramic tribo-pairs in sliding contact is their compatibility with environmentally friendly lubricants[8], especially water-based lubricants, which are regarded as the perfect candidate compared with conventional oil and grease lubricants, owing to their excellent properties of eco-friendliness, good fluidity and superb thermal conductivity. Waterbased lubricants have been widely researched and applied in the fields of ship propulsion systems [9], marine transportation, oil and coal mining [10], deep-seabed mining robot vehicles and so on. At low speeds and high load conditions, additives including surfactants [11] or nanoparticles[12] are added to improve the boundary lubrication of water. In addition, some laboratory studies have shown that ultra-low friction or superlubricity could be achieved with ceramic-ceramic tribo-pairs under acidic aqueous solutions. [13-15] Up to now, the anti-friction mechanisms involved in the water-based lubrication of ceramic tribo-pairs have been attributed to adsorbed boundary films, tribochemical reactions [15], hydration lubrication, double electric layer repulsion and hydrodynamic lubrication effect[16]. 
Like oil lubrication and solid lubrication, reducing friction is not the sole objective of water-based lubrication. For the past decades, many researchers have been pursuing active control of friction and wear,[17] in which some special external mechanical, thermal, optical, electrostatic or electrochemical stimuli are imposed to tribosystems in order to actively tune the magnitude of friction in-situ. Particularly, effects of an electric field on tribological behavior of materials have been mostly studied in various aqueous and nonaqueous solutions with or without additives of various kinds of surfactants [18], ionic liquids[19] and nanoparticles[20, 21]. This emerging technology is usually called as potential controlled boundary or potential controlled friction. At present, the basic mechanisms of potential controlled boundary lubrication have been almost clarified, including the reversible adsorption/desorption and morphology transition of the responsive constituents of additives at relatively mild electric field conditions[22], and the electrochemical or triboelectrochemical reactions at strong electric fields, such as electrolysis of the solution[23, 24].

In the previous potential controlled boundary lubrication experiments, however, it is required that at least one part of the tribo-pairs to be controlled is a conductor and serves as the working electrode[17], which means it is not applicable to the tribopairs made of insulators such as ceramic-ceramic, polymer-polymer or ceramicpolymer pairs. In addition, in water-based lubrication, the surface potential acted on the sliding surfaces should be strictly limited to the range of electrochemical window for prevention of excessive corrosion of the working electrode. In this work, an alternative design of electrochemical cell, where the working and counterpart 
electrodes are completely separated from the sliding pairs, is proposed, and thus can be applied to all tribo-pairs made of any kinds of materials. To demonstrate the effect of the new design, tribology tests on $\mathrm{ZrO}_{2}$ ball on $\mathrm{Al}_{2} \mathrm{O}_{3}$ plate in sodium dodecyl sulfate (SDS, a common surfactant) aqueous solution were conducted under varying electric field conditions. It has been discovered that the friction coefficient can be tuned in a relative wide range as like in the cases of ceramic balls on metal plates reported previously[18], but with a longer response time. An indirect adsorption model has been proposed to explain the observations. Furthermore, it is found that adding inorganic salts or increasing the concentration of SDS can shorten the response time. The mechanism has been elucidated by analyzing the state of SDS micelles in liquid phase and at the solid-liquid interface.

\section{Experimental details}

\subsection{Materials}

Sodium dodecyl sulfate (SDS, 95\%, Beijing Solarbio Science \& Technology Co., Ltd.) was selected as the anti-friction additive in water in this work. The SDS and $\mathrm{NaCl}$ (99.5\%, Sinopharm Chemical Reagent Beijing Co., Ltd.) were dissolved in the deionized water (DI water) with resistivity of $18.2 \mathrm{M} \Omega \cdot \mathrm{cm}$ in the concentration range of $0 \mathrm{mM}$ to $10.0 \mathrm{mM}$. The prepared aqueous solutions were used in the tribology tests.

$\mathrm{ZrO}_{2}$ balls with diameter of $6.35 \mathrm{~mm}$ and surface roughness $\mathrm{Ra}$ of $\sim 20 \mathrm{~nm}$ were used as the upper friction pair. $\mathrm{Al}_{2} \mathrm{O}_{3}$ plates $\left(10 \times 20 \times 2 \mathrm{~mm}^{3}\right)$ was used as the lower friction pair, and its Ra was about $3 \mu \mathrm{m}$ measured on a 3D optical surface profilometer 
(Zygo NexView, USA). A steel ball holder was designed and served as the working electrode, and a steel plate $\left(20 \times 20 \times 2 \mathrm{~mm}^{3}\right)$ placed aside the $\mathrm{Al}_{2} \mathrm{O}_{3}$ plate was used as the counter electrode, as shown in Figure.1. In the three-electrode system, an $\mathrm{Ag} / \mathrm{AgCl}$ electrode was used as the reference electrode with $\mathrm{E}_{0}=0.2224 \mathrm{~V}$ versus the standard hydrogen electrode.

\subsection{Friction tests and electrochemical measurements}

Figure.1 shows the experimental setup, which merges a tribometer (UMT-3, Bruker, Germany) with either an electrochemical workstation (PGSTAT302N, Auto, Switzerland) or a direct current (DC) power supply. Before friction tests, both the upper and lower specimens were cleaned in an ultrasonic bath with acetone, ethanol and DI water sequentially, and dried with compressed air. The force applied to the ball-on-flat surface was $3 \mathrm{~N}$, corresponding a pressure of $0.98 \mathrm{GPa}$. Tests were performed at the sliding speed of $10 \mathrm{~mm} / \mathrm{s}$ over a $5 \mathrm{~mm}$ track. The reciprocating frequency was set at $1 \mathrm{~Hz}$. All the tests were carried out at room temperature about $25^{\circ} \mathrm{C}$.

An external electric field was applied on either with a two-electrode system or a three-electrode system. The inner and outer diameters of the bottom ring for the ball holder (worked as the working electrode in the electrochemical measurements) were $4.9 \mathrm{~mm}$ and $9.9 \mathrm{~mm}$, respectively. During the friction tests and electrochemical measurements, the submergence of the ball holder into the SDS solution was kept in the range between $1 \sim 2 \mathrm{~mm}$, while the counter electrode steel plate was always 
immersed in the solution. For the three-electrode system, the reference electrode of $\mathrm{Ag} / \mathrm{AgCl}$ was placed close to the ball holder with a gap about $1 \mathrm{~mm}$. A negative value of voltage (in both of the two-electrode and three-electrode systems) means that the working electrode is connected to the negative pole of the DC supply or the electrochemistry workstation, and vice versa.

Considering that the open circuit potential (OCP) of the steel holder (working electrode in Figure.1) in SDS aqueous solution was about -0.023 V versus $\mathrm{Ag} / \mathrm{AgCl}$, during the experiments the surface potential of the holder was set either as $-0.6 \mathrm{~V}$ or $+0.2 \mathrm{~V}$ when the three-electrode system was used. When switched to the two-electrode system, 2 Volts was applied on either negatively or positively, which was a little bit higher value compared with that in the three-electrode system. The surface potential or voltage ranges was so selected that profound electrolysis of the test SDS solution was prevented. After friction tests, the morphologies of the $\mathrm{Al}_{2} \mathrm{O}_{3}$ plate were inspected on an optical microscope (Keyence, Japan) and a 3D optical surface profilometer (Zygo NexView).

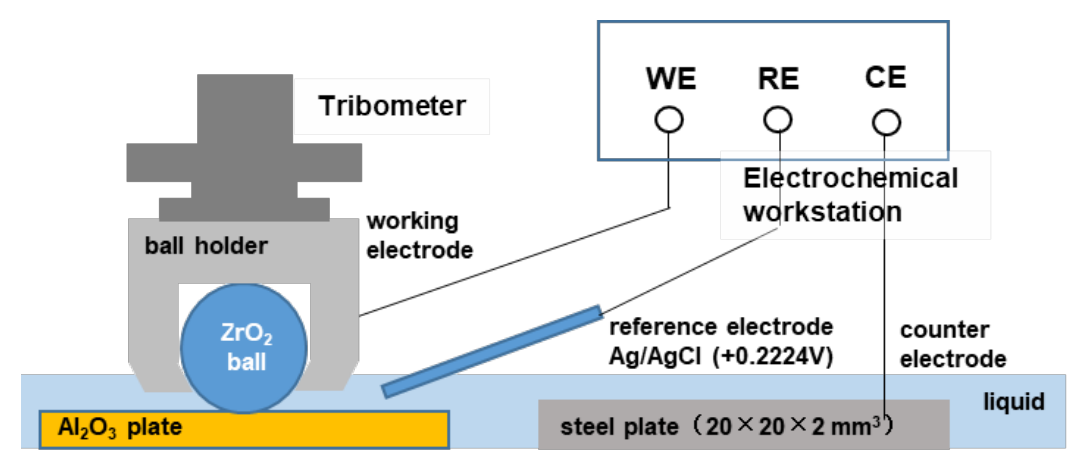

Figure.1 Schematic diagram of the testing module combining an electrochemical workstation (or a DC power supply) and a tribometer 
2.3 Characterization of adsorption behavior at solid-liquid interface

The zeta potential of the SDS aqueous solutions was measured on a zetasizer (Malvern, U.K.). A quartz crystal microbalance (QCM, Q-sense E4 system, Biolin Scientific, Sweden) was used to measure adsorption/desorption of SDS molecules on solid surfaces. The changes of both resonance frequency $(\Delta f)$ and dissipation $(\Delta D)$ due to the mass variations of ions or molecules on the $\mathrm{Al}_{2} \mathrm{O}_{3}$ coated quartz crystal sensors per unit area were recorded by the QCM. The adsorption measurements were performed in the following 4 steps. The first step is to start measurement in air to find the base resonance frequencies till approaching relatively stable values. The second step is to inject pure water into the testing module by an external pump with the speed of $200 \mu \mathrm{L} / \mathrm{min}$ through a PTFE tube of $0.75 \mathrm{~mm}$ in inner diameter and $22.5 \mathrm{~cm}$ in length, monitoring the variations of $\Delta D$ and $\Delta f$ in water till they keep on stable values for at least $180 \mathrm{~s}$. The third step is to switch the injection from pure water to the SDS solution to be tested, recording the changes in resonance frequencies and dissipation caused by adsorption or desorption of the ions or surfactants for the third, fifth, seventh, and ninth overtones at $298 \mathrm{~K}$. The final step is to re-inject pure water into the testing module for cleaning the conduit and vessel.

If the measured value of $\Delta D$ is smaller than $10^{-6}$, then the adsorbed film can be regarded as rigid, and Sauerbrey equation can be used to calculate the adsorbed mass changes $(\Delta m)$ according to the frequency changes, as shown in Equation (1).[25, 26]

$$
\Delta m=-C_{0} \frac{\Delta f}{N}
$$

where $C_{0}$ is a constant of $17.7 \mathrm{ng} \cdot \mathrm{Hz}^{-1} \cdot \mathrm{cm}^{-2}$, which is related to the properties of the 
quartz crystal, and $N$ is the overtone of the oscillations. In this work, the fifth overtone was used for the calculation because of its better signal-to-noise ratio among the different overtones.

\section{Results and discussions}

\subsection{Active control of friction between ceramics under water lubrication} conditions

Figures.2 and 3 show the friction test results with two-electrode and threeelectrode systems respectively. After a running-in period lasting $800 \mathrm{~s}$, the applied voltage (Figure.2) or the surface potential (Figure.3) was periodically changed between $+2 \mathrm{~V}$ and $-2 \mathrm{~V}$ (Figure.2) or between $+0.2 \mathrm{~V}$ and $-0.6 \mathrm{~V}$ (Figure.3). We can see that the coefficient of friction drops to 0.12 in the periods of the positive voltage (Figure.2) or positive surface potential (Figure.3), while goes up to about 0.35 when the voltage or potential is switched to negative. In the last stage of $2000-2200 \mathrm{~s}$, the power supply is off, and the coefficient of friction goes down to 0.12 . There is no doubt that the friction coefficient between the ceramic ball and plate has been modulated by the applied electric field with either the two-electrode or three-electrode method.

Differing from the electrically tunable friction between ceramic balls and metal plates reported by the authors previously[18, 22], both parts of the ceramic tribo-pairs in this study are insulator, the surface potential of which could not be changed by the electrode system shown in Figure.1. Why is the friction between ceramics responsible 
to the changes in the applied voltage or surface potential on the steel holder? It should be noted that the steel holder is placed in a position so close to the contact area (with a gap of $1 \mathrm{~mm}$ ), that the change in the distribution of SDS molecules or ions in the solution, which depends on the electric field between the working electrode and the counter electrode, indirectly affects the adsorption of lubricious SDS anions on the contact surface, and thus the boundary lubrication state. This is probably the mechanism responsible to the reversible changes in friction coefficient shown in Figures.2 and 3. In the following, more experimental evidences and analyses are provided.

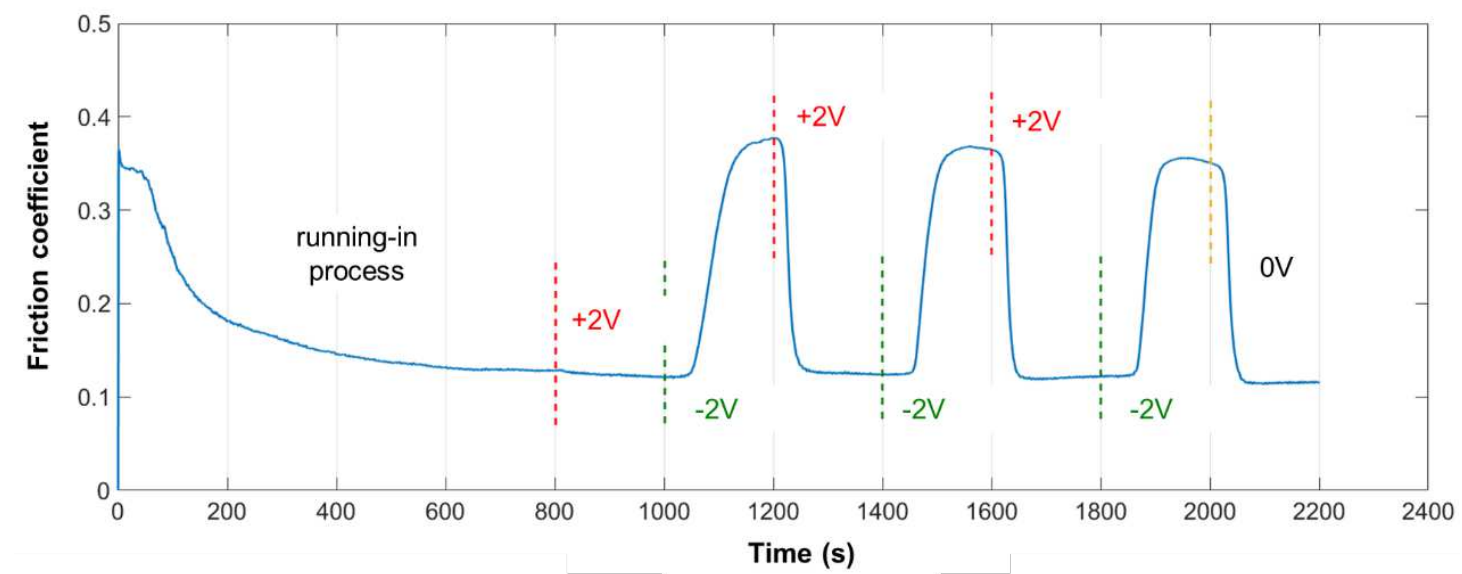

Figure. 2 Friction coefficient of the $\mathrm{Al}_{2} \mathrm{O}_{3}$ plate vs. $\mathrm{ZrO}_{2}$ ball versus time with the mixed solution of $1 \mathrm{mM}$ SDS and $10 \mathrm{mM} \mathrm{NaCl}$ working as the lubricant under different applied potentials in two-electrode system. 


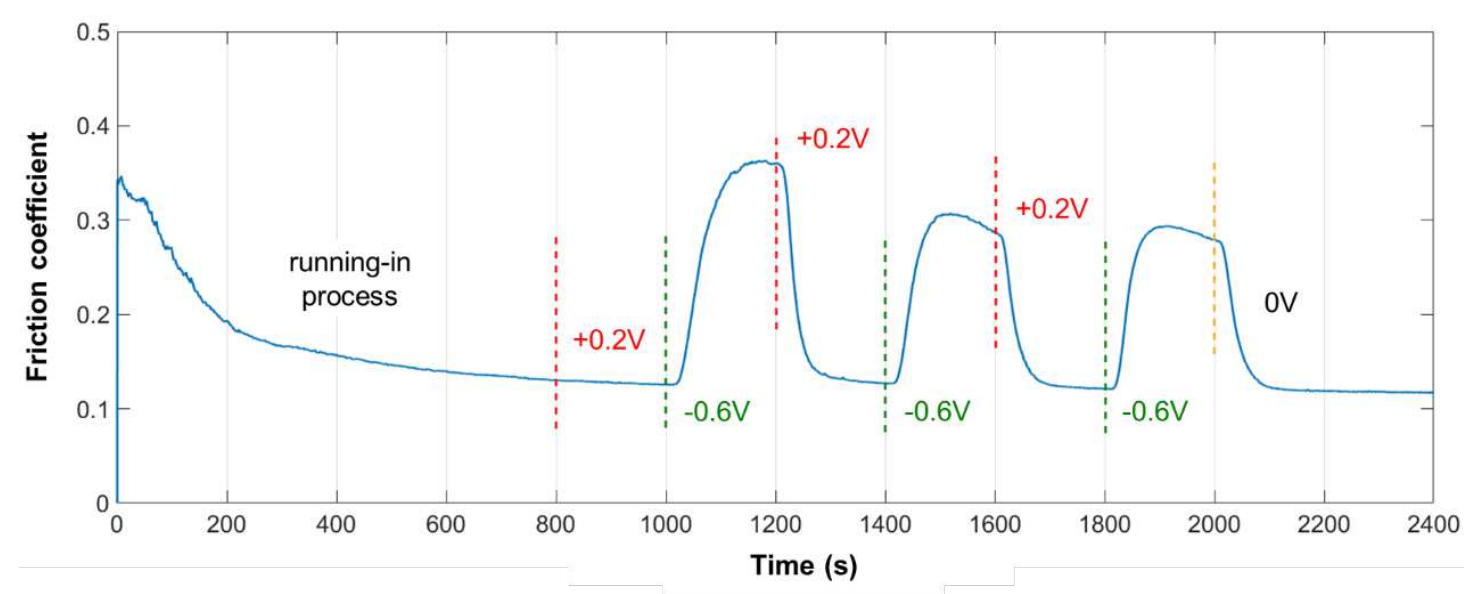

Figure. 3 Friction coefficient of the $\mathrm{Al}_{2} \mathrm{O}_{3}$ plate vs. $\mathrm{ZrO}_{2}$ ball versus time with the mixed solution of $1 \mathrm{mM}$ SDS and $10 \mathrm{mM} \mathrm{NaCl}$ working as the lubricant under different applied surface potentials of the working electrode near the contact area in three-electrode system.

Figure.4 shows the friction and wear results under three different fixed electric conditions, $\mathrm{OCP},+0.2 \mathrm{~V}$ and $-0.6 \mathrm{~V}$. OCP means there is no external electric field applied between the electrodes, and thus the surface potential of the working electrode (i.e. steel holder) is at its natural potential of $-0.023 \mathrm{~V}$ versus $\mathrm{Ag} / \mathrm{AgCl}$. The COF results are consistent with those shown in Figure.3. The running-in time (for the COF from $\sim 0.35$ to 0.12 ) decreased from $300 \mathrm{~s}$ (under OCP) to $200 \mathrm{~s}$, when a positive surface potential of $+0.2 \mathrm{~V}$ was applied constantly. The COF was in the range of $0.3 \sim 0.4$ when the surface potential was kept on $-0.6 \mathrm{~V}$. The wear scars of the $\mathrm{ZrO}_{2}$ balls after the friction tests under the different electric conditions are shown in Figures.4b-d. When the surface potential of the working electrode was $+0.2 \mathrm{~V}$, the width of wear scar reduced to $578 \mu \mathrm{m}$, compared with the wear size of $606 \mu \mathrm{m}$ at the OCP condition. When the surface potential was $0.6 \mathrm{~V}$, however, wear scar size increased to $632 \mu \mathrm{m}$. The tracks on the $\mathrm{Al}_{2} \mathrm{O}_{3}$ plates have been also inspected on an optical microscope and a 3D optical surface profilometer. Under the 
condition of OCP or the positive surface potential, the wear tracks on the $\mathrm{Al}_{2} \mathrm{O}_{3}$ plates were almost invisible, because of the higher hardness of the $\mathrm{Al}_{2} \mathrm{O}_{3}$ comparing with the $\mathrm{ZrO}_{2}$ ball as well as relative low friction. At negative potential of $-0.6 \mathrm{~V}$, some abrasive particles with the size about $100 \mu \mathrm{m}$ can be observed on the track. The observed characteristics of wear under different surface potentials accord with that of the COF.

(a)
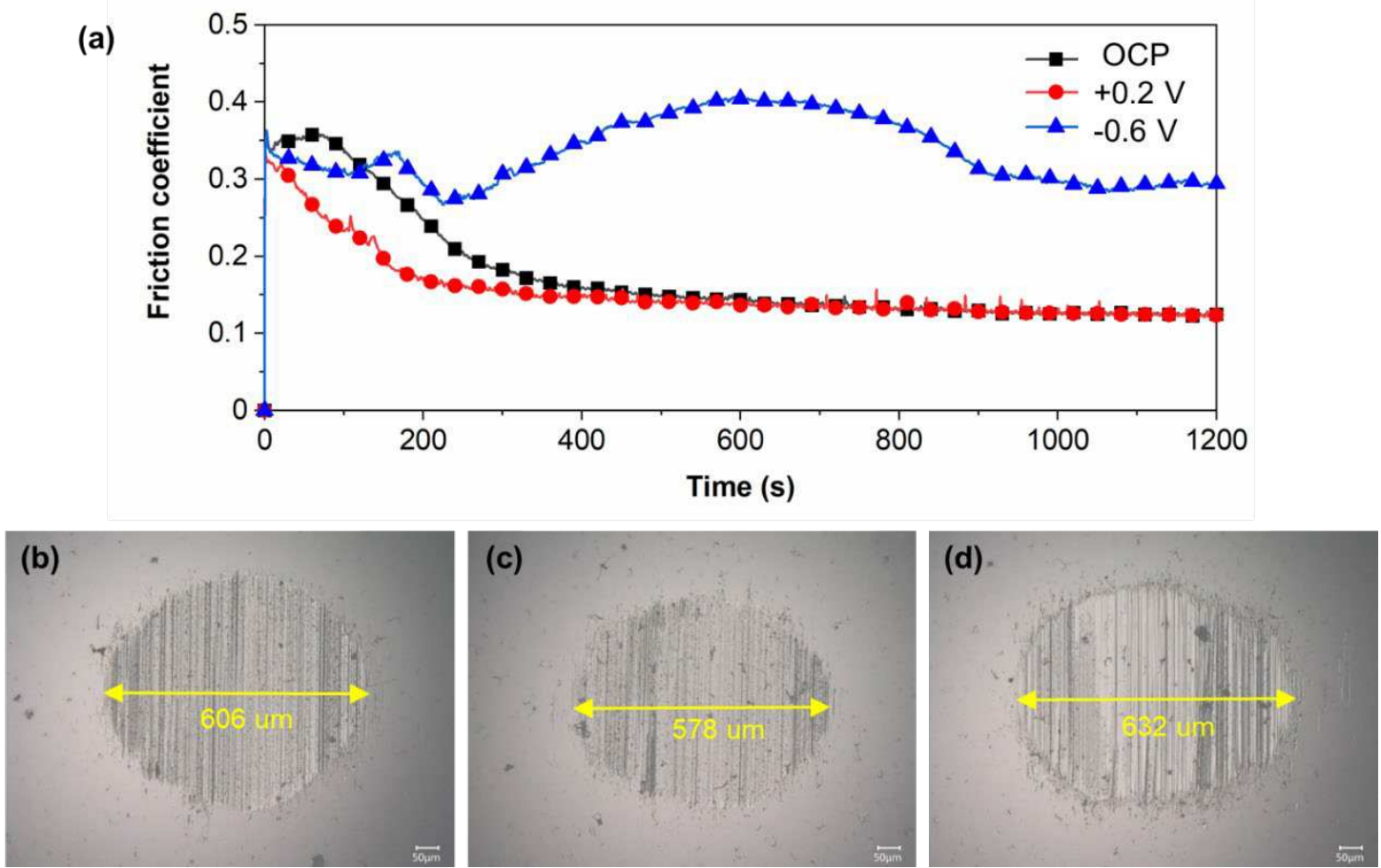

Figure. 4 Friction coefficients of the $\mathrm{ZrO}_{2}$ ball vs. $\mathrm{Al}_{2} \mathrm{O}_{3}$ plate under boundary lubrication in the mixed solution of $1 \mathrm{mM}$ SDS and $10 \mathrm{mM} \mathrm{NaCl}$ under different applied surface potentials (a), and micrographs of the wear scars on the top of the $\mathrm{ZrO}_{2}$ balls under OCP (b), positive potential of $+0.2 \mathrm{~V}$ (c) and negative potential of $-0.6 \mathrm{~V}$ (d) for the working electrode.

It is worth noting that the changes in COF delayed in some extent behind the applied voltage or potential as shown in Figures.2 and 3. The response behavior can be displayed more clearly in a shorter time scale in Figure.5. Figures.5a and 5b present the variations of COF with time when the surface potential was switched from +0.2 $\mathrm{V}$ to $-0.6 \mathrm{~V}$ or $0 \mathrm{~V}$ and from $-0.6 \mathrm{~V}$ to $+0.2 \mathrm{~V}$ or $0 \mathrm{~V}$, respectively. Both of the pictures 
show that there is a time lag of $10 \mathrm{~s}$ or more behind the surface potential. Furthermore, the COF takes several tens of seconds $(60 \sim 80 \mathrm{~s})$ to reach a relatively stable value.

On the other hand, the changes in the current were almost synchronous with the surface potential as shown in Figures.5c and 5d. In Figure.5c, the current is at the maximum value at the beginning of switching, and gradually approaches to $-0.13 \mathrm{~mA}$ after $5 \mathrm{~s}$. The insert indicates that there exists a small cyclic fluctuation of current with the frequency of $1 \mathrm{~Hz}$, which is considered to be caused by the reciprocating motion of the $\mathrm{Al}_{2} \mathrm{O}_{3}$ plate. When the surface potential was switched from the negative value of $-0.6 \mathrm{~V}$ to zero or the positive value of $+0.2 \mathrm{~V}$, the current decayed from sub$\mathrm{mA}$ to $\mu \mathrm{A}$ rapidly in $2 \mathrm{~s}$, and then further decreased to about $0.3 \mu \mathrm{A}$ and $0.1 \mu \mathrm{A}$ for the cases of $+0.2 \mathrm{~V}$ and $0 \mathrm{~V}$ surface potentials respectively, as shown in Figure. $5 \mathrm{~d}$.

Comparing Figures.5a and $5 \mathrm{c}$ with Figures.5b and $5 \mathrm{~d}$, it is evident that the change of COF is behind of the current, or the electromigration of ions in the solution under the electric field between the electrodes. The time lag, in the order of tens of seconds, is much longer than that in the cases of ceramic/electrode contacts found previously[18], in which the response time is just a few seconds or less. 

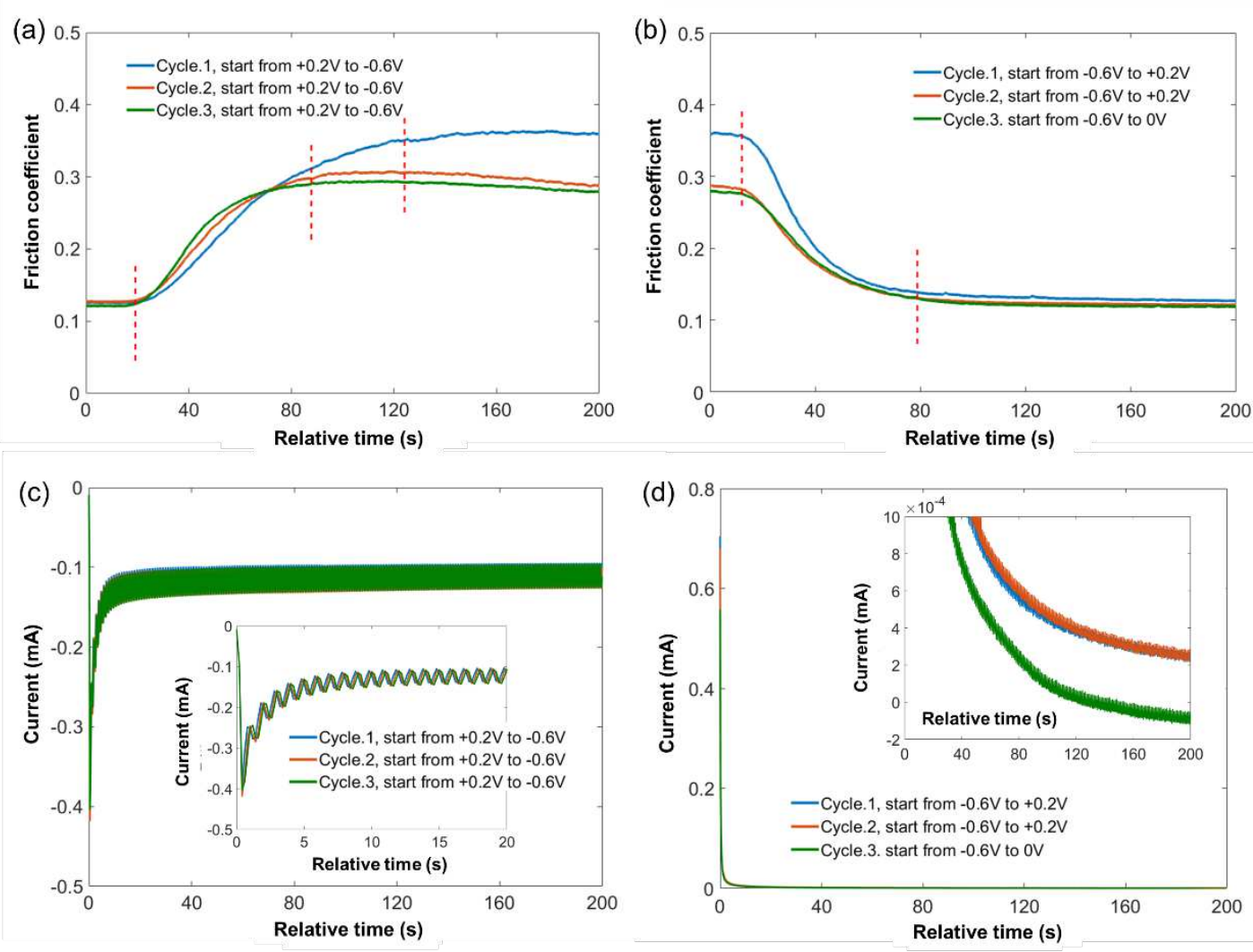

Figure.5 Relationship between the COF, electric current and time, when the surface potential was controlled and changed by electrochemical workstation. The COF over time when the surface potential was changed from $+0.2 \mathrm{~V}$ to $-0.6 \mathrm{~V}$ at $0 \mathrm{~s}$ shown in (a) and from $-0.6 \mathrm{~V}$ to $+0.2 \mathrm{~V}$ or $0 \mathrm{~V}$ at $0 \mathrm{~s}$ shown in (b). The current over time when the surface potential was changed from $+0.2 \mathrm{~V}$ to $-0.6 \mathrm{~V}$ at $0 \mathrm{~s}$ shown in (c) and from $-0.6 \mathrm{~V}$ to +0.2 $\mathrm{V}$ or $0 \mathrm{~V}$ at $0 \mathrm{~s}$ shown in (d).

\subsection{Effect of the SDS concentration}

In the above experiments, the mixture solution of $1 \mathrm{mM}$ SDS and $10 \mathrm{mM} \mathrm{NaCl}$ was used as the lubricant. In order to explore the effects of additives and their components on the lubrication behaviors, the following experiments have been carried out.

Firstly, pure water, pure SDS solutions with different concentrations as well as $10 \mathrm{mM} \mathrm{NaCl}$ solution were compared as the lubricant of the ceramic tribo-pairs. The friction results are shown in Figure.6. When no SDS is added in pure water or in the 
$10 \mathrm{mM} \mathrm{NaCl}$ solution, the $\mathrm{COF}$ is relatively high, about 0.45 . The addition of $\mathrm{NaCl}$ makes the COF more stable, rather than decreases it effectively. However, when the SDS concentration is greater than or equals to $1 \mathrm{mM}$, the COF decreases to 0.12 . This implies that it is the SDS surfactant rather than $\mathrm{NaCl}$ salt that plays the role of lubricious constituent in the solution. When the concentration of SDS is $1 \mathrm{mM}$, the COF does not respond to the change in the surface potential, although it keeps a low value. This is different from the results shown in Figure. 3 above, where $10 \mathrm{mM} \mathrm{NaCl}$ was added into the $1 \mathrm{mM}$ SDS solution. As the concentration of SDS increases to 2 $\mathrm{mM}$ or greater, the electric response of COF becomes more and more evident. According to the knowledge of colloidal chemistry, both of the concentrations of the salts and surfactants affect the surfactant micellar state in the solutions. Hence, the electric response of COF is considered to depend on the micellar state of the SDS in solutions.

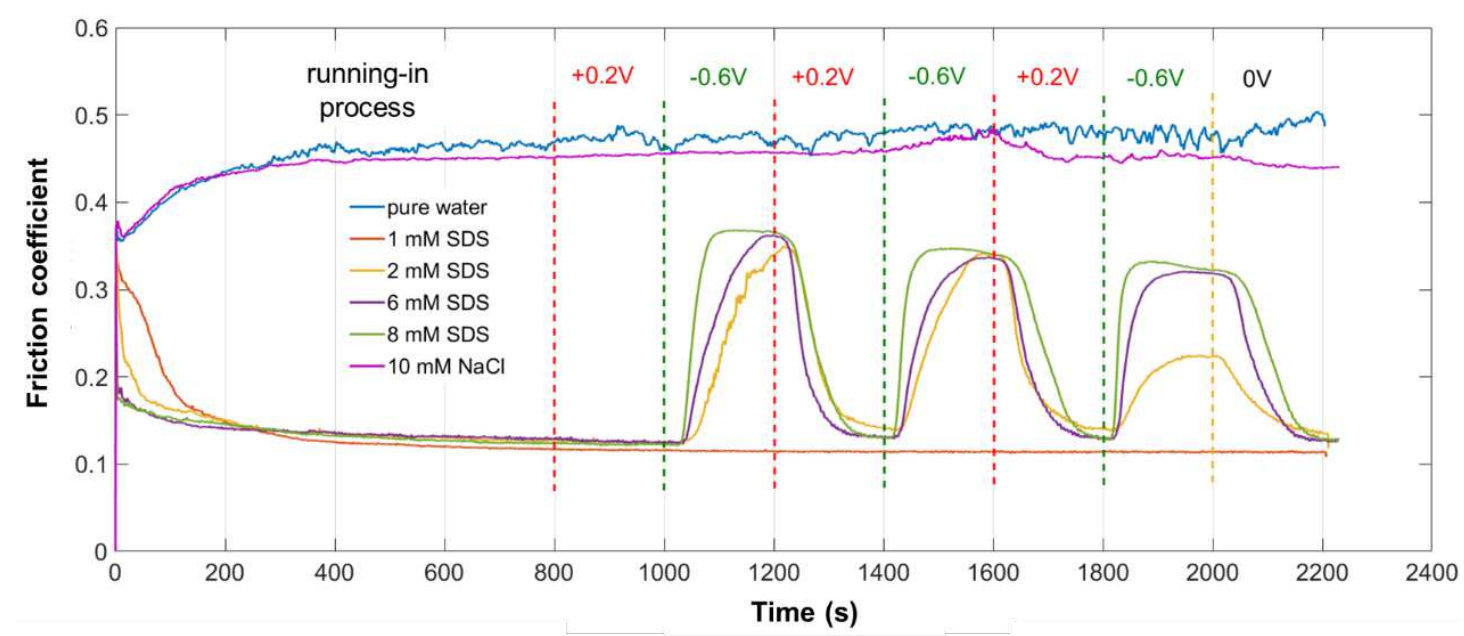

Figure.6 Friction coefficient of the $\mathrm{Al}_{2} \mathrm{O}_{3}$ plate vs. $\mathrm{ZrO}_{2}$ ball versus time with pure $\mathrm{H}_{2} \mathrm{O}$ or single solution working as the lubricant under different applied potentials of the working electrode near the contact area. 
To further explore the influence of the mixture in the solutions on the behavior of the potential controlled boundary lubrication systems, the mixture solutions with different molar ratios of SDS to $\mathrm{NaCl}, 1: 1,1: 2,1: 5,1: 10,1: 20$ and 1:50, were prepared and tested, and the results are shown in Figure.7. For the mixtures with $1 \mathrm{mM}$ SDS, when the concentration of $\mathrm{NaCl}$ is $1 \mathrm{mM}$ or $2 \mathrm{mM}$, their lubrication behavior is similar to that of the $1 \mathrm{mM}$ SDS solution without adding $\mathrm{NaCl}$. The COFs in the above tests stabilize at about 0.12 after the running-in process, while the change of COF with time and surface potential is not obvious. However, when the concentration of $\mathrm{NaCl}$ increases to $5 \mathrm{mM}$ in the $1 \mathrm{mM}$ SDS solution, the COF increases from 0.12 to 0.20 when a negative surface potential of $-0.6 \mathrm{~V}$ is applied, and then decreases to $0.12 \sim 0.13$ when a positive surface potential of $+0.2 \mathrm{~V}$ is applied. According to the results in Figures. 3 and 7 , for the $1 \mathrm{mM}$ SDS solutions, increasing the $\mathrm{NaCl}$ concentrations in a range of $0 \sim 10 \mathrm{mM}$ cannot improve the lubrication performance of the system, but it plays an important role in improving the response of COF to electric field.

For the $0.5 \mathrm{mM}$ SDS solutions with different contents of $\mathrm{NaCl}$, the running-in time for the COF dropping from $0.3 \sim 0.4$ to $\sim 0.12$ increases to about $800 \mathrm{~s}$, which is much longer compared with the time of $200 \mathrm{~s}$ in the case of the $1 \mathrm{mM}$ SDS solution. When the SDS concentration is further reduced to $0.2 \mathrm{mM}$, the running-in time further increases to more than $1800 \mathrm{~s}$. 


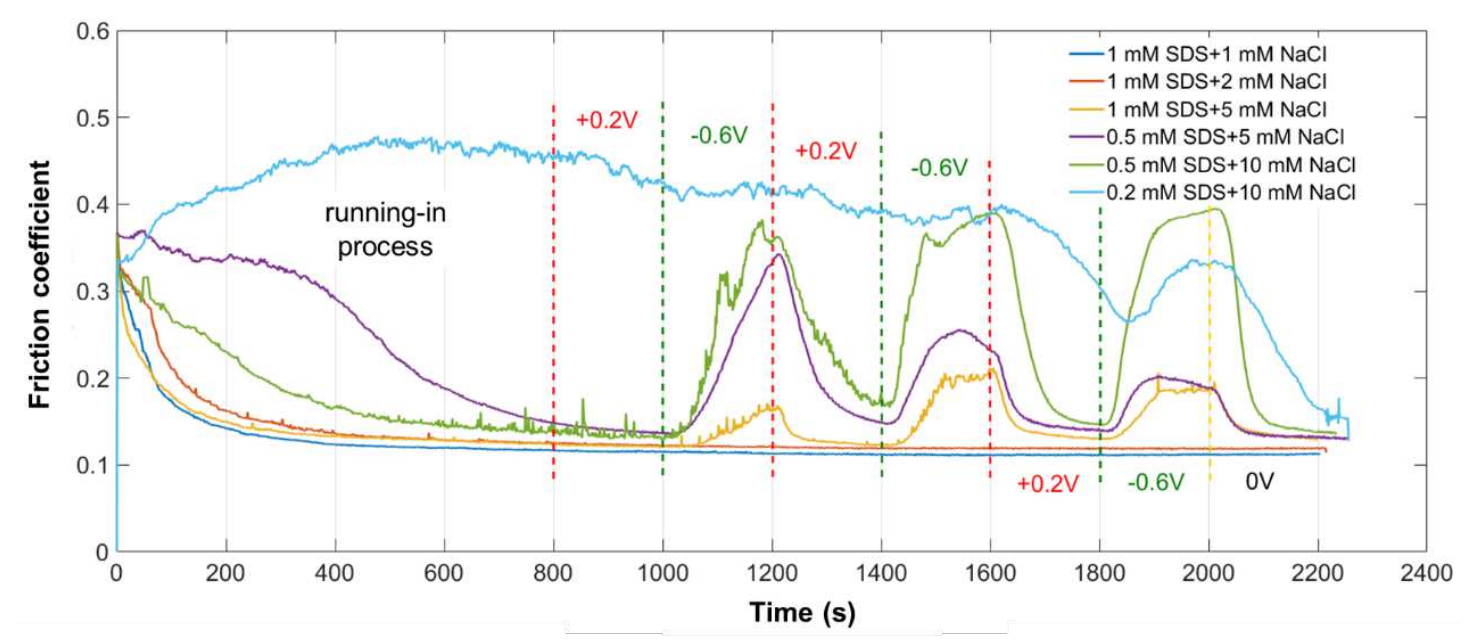

Figure. 7 Friction coefficient of $\mathrm{Al}_{2} \mathrm{O}_{3}$ plate vs. $\mathrm{ZrO}_{2}$ ball over time in the mixed solutions with different contents of SDS and $\mathrm{NaCl}$ under different applied potentials of the working electrode near the contact area.

To further explore the effect of SDS concentration, friction the adsorption behaviors for the solutions with different SDS concentrations in the absence and the presence of $10 \mathrm{mM} \mathrm{NaCl}$ were investigated respectively, and the results are shown in Figure 8 . Here, the adsorption mass of the additives in the three different solutions were converted according to Equation (1) from the QCM data. The results indicate that whether $\mathrm{NaCl}$ is present or not, the $\mathrm{COF}$ has a certain relationship with the adsorption amount of SDS. When the adsorbed mass is above $150 \mathrm{ng} / \mathrm{cm}^{2}$, the COF decreases to $0.1 \sim 0.2$ within the testing time of $600 \sim 900 \mathrm{~s}$. However, when the adsorbed mass is below that value, the COF is about $0.35 \sim 0.45$. For the pure SDS solutions, the critical concentration is about $0.4 \sim 0.5 \mathrm{mM}$, as shown by the blue dotted line in Figure.8a. For the mixtures with $10 \mathrm{mM} \mathrm{NaCl}$, the minimum SDS concentration for the lower COF is about $0.2 \sim 0.3 \mathrm{mM}$, as shown in Figure. $8 \mathrm{~b}$.

Combining the above results, it is evident that the SDS concentration affects the 
adsorption amount at the interface between the $\mathrm{Al}_{2} \mathrm{O}_{3}$ plate and the solution, and then change the friction behavior of the system. Moreover, the presence of $\mathrm{NaCl}$ can also influence the adsorption amount at the solid-liquid interface and affect the friction behavior.
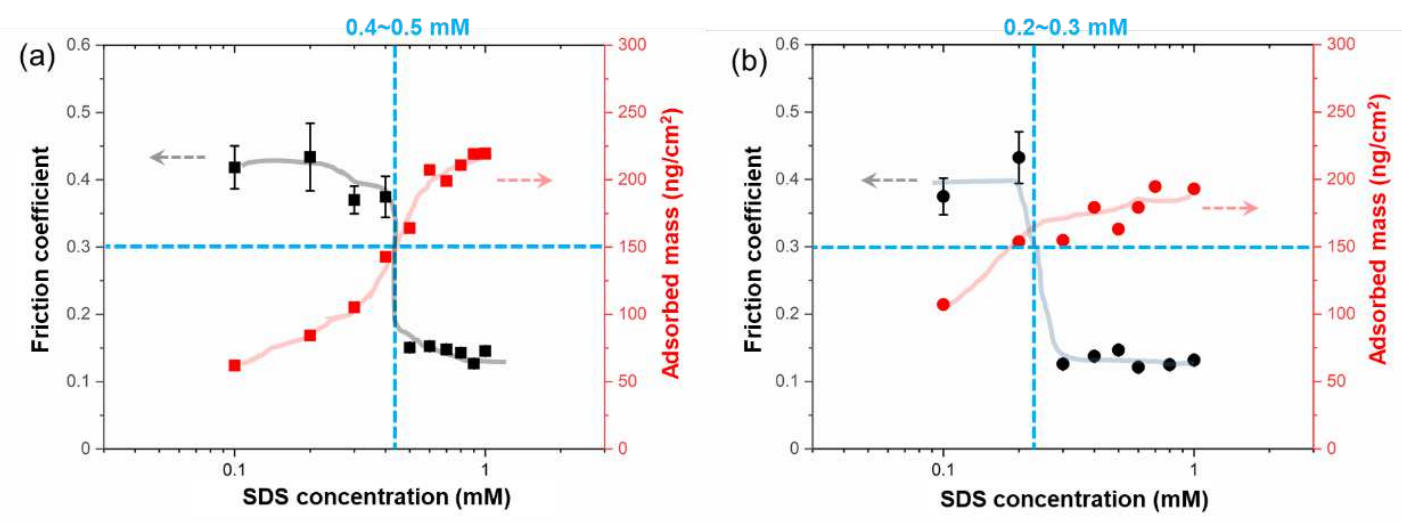

Figure. 8 Friction coefficient and adsorption behaviors for the solutions with different SDS concentrations in the absence (a) and the presence of $10 \mathrm{mM} \mathrm{NaCl} \mathrm{(b).}$

\subsection{Effect of inorganic salt}

According to the above analysis, the adsorption and desorption behavior of the SDS in liquid is the key path for controlling the electric response as well as the boundary lubrication of the tribo-systems. Meanwhile, the presence of inorganic salts can affect the state of the SDS in aqueous solution, thereby affecting the tribological behavior as well as the adsorption and desorption behavior as shown in Figures.7 and 8. To understand the effect of the added $\mathrm{NaCl}$ salt on the SDS structures in the solutions, further experiment work has been done.

First, the zeta potentials of $1 \mathrm{mM}$ SDS solutions with and without $10 \mathrm{mM} \mathrm{NaCl}$ were measured respectively. As you know, zeta potential is generally used to characterize the charge and dispersion stability of colloidal particles in suspension. 
Hence, this method can also be used to characterize the electrical properties and stability of the SDS micelles in high concentration (close to the $\mathrm{CMC}$ at $25^{\circ} \mathrm{C}$ ) solutions. The result shows that the zeta potentials of $1 \mathrm{mM}$ SDS without and with 10 $\mathrm{mM} \mathrm{NaCl}$ are $-58.5 \pm 0.7 \mathrm{mV}$ and $-71.7 \pm 2.9 \mathrm{mV}$ respectively. This result means that the presence of $\mathrm{NaCl}$ promotes the formation of the SDS micelles, further reducing their zeta potentials, and implies that the electric response of COF to the applied electric field is enhanced.

Next, the effect of $\mathrm{NaCl}$ on the SDS state at solid-liquid interface was further studied with QCM characterization. The measurement procedure is as described above. As shown in Figure 9, the adsorption films in the three cases of different $\mathrm{NaCl}$ concentrations can all be regarded as rigid films, and all of the obtained three adsorption isotherms yield the Langmuir type adsorption.

Figure. $9 \mathrm{~b}$ shows the adsorption and desorption behaviors at the interface between the $\mathrm{Al}_{2} \mathrm{O}_{3}$ coated quartz crystal sensor and $10 \mathrm{mM} \mathrm{NaCl}$ solution. A baseline tested in pure $\mathrm{H}_{2} \mathrm{O}$ was obtained in the first $180 \mathrm{~s}$. Then $10 \mathrm{mM} \mathrm{NaCl}$ solution was injected with the same pumping speed. After $40 \sim 50 \mathrm{~s}$, the solution entered the module through an inlet tube. During the period of the solution into the module, the $\mathrm{NaCl}$ concentration of the liquid in the module can be regarded as from 0 to $10 \mathrm{mM}$. According to Figure.10b, it takes about $180 \mathrm{~s}$ for the adsorption equilibrium. Comparing with the baseline in pure $\mathrm{H}_{2} \mathrm{O}$, the equilibrium adsorption capacity of $\mathrm{NaCl}$ is about $33 \mathrm{ng} / \mathrm{cm}^{2}$. Pure $\mathrm{H}_{2} \mathrm{O}$ is then injected into the module instead of the $10 \mathrm{mM}$ $\mathrm{NaCl}$ solution at $900 \mathrm{~s}$. Due to the diffusion and competitive adsorption of the 
adsorbents at the interface, the adsorption capacity starts to decrease until it reaches to the desorption equilibrium in pure $\mathrm{H}_{2} \mathrm{O}$ after about 180 s.

Figures.9c and 9d present the adsorption and desorption behavior of the $1 \mathrm{mM}$ SDS solution and the mixtures of $1 \mathrm{mM}$ SDS and $10 \mathrm{mM} \mathrm{NaCl}$ respectively. The equilibrium adsorption capacity in Figure.9c is about $220 \mathrm{ng} / \mathrm{cm}^{2}$, indicating that adsorption capacity of SDS on $\mathrm{Al}_{2} \mathrm{O}_{3}$ solid is greater than that of the $\mathrm{Na}^{+}$and $\mathrm{Cl}^{-}$ shown in Figure.9b. Moreover, it takes about $520 \mathrm{~s}$ to reach the adsorption equilibrium from pure $\mathrm{H}_{2} \mathrm{O}$ to $1 \mathrm{mM}$ SDS solution, and takes about $500 \mathrm{~s}$ for the desorption process.
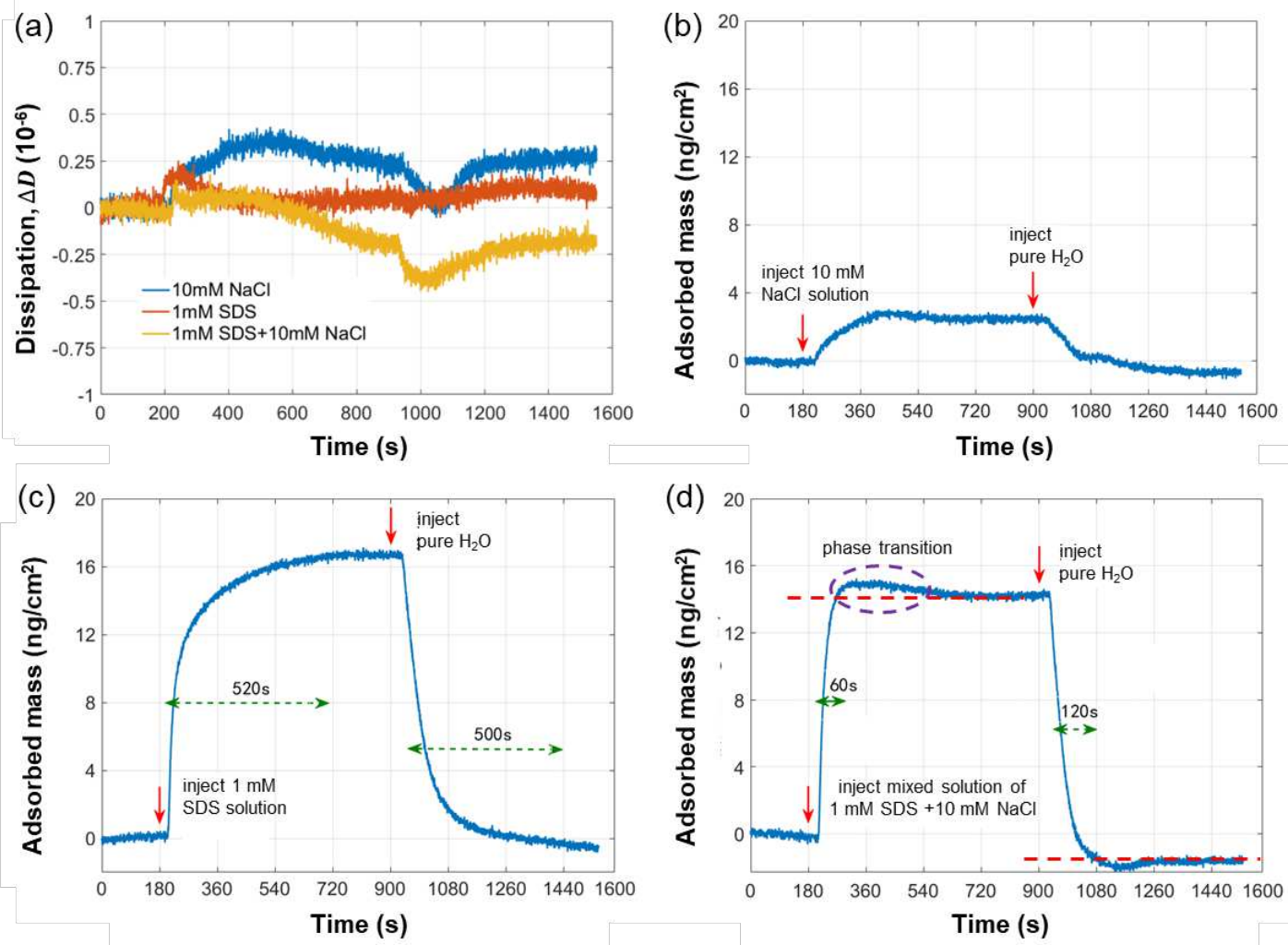

Figure.9 Adsorption behaviors of the additives in three different solutions by QCM, including the variation of dissipation factors with time in different solutions (a) and the curves of adsorption capacity and time in different solutions of $10 \mathrm{mM} \mathrm{NaCl}$ (b), $1 \mathrm{mM}$ SDS (c) and $1 \mathrm{mM} \mathrm{SDS}+10 \mathrm{mM} \mathrm{NaCl}$ (d). All of the above results were obtained when pure $\mathrm{H}_{2} \mathrm{O}$ was tested to be the base line, then the solution was injected at $180 \mathrm{~s}$ for the adsorption tests, and finally the pure $\mathrm{H}_{2} \mathrm{O}$ was injected at $900 \mathrm{~s}$ for the desorption testing. 
The test temperature was held at $25^{\circ} \mathrm{C}$.

However, for the mixtures of $1 \mathrm{mM} \mathrm{SDS}$ and $10 \mathrm{mM} \mathrm{NaCl}$, the time required for adsorption and desorption equilibrium is about $60 \mathrm{~s}$ and $120 \mathrm{~s}$ respectively as shown in Figure.9d, which are significantly shorter than the time required for the $1 \mathrm{mM}$ SDS without $\mathrm{NaCl}$ in Figure.9c. In addition, the equilibrium adsorption capacity is about $193 \mathrm{ng} / \mathrm{cm}^{2}$ in the mixture solution. Comparing with the adsorption isotherm in Figure.9c, the relative low adsorption capacity is considered to be caused by the $\mathrm{Cl}^{-}$ ions in the mixture, which occupy the positions of $\mathrm{DS}^{-}$anions in the condition of 1 mM SDS solution. In this work, it is assumed that there is no overlap and interaction between different kinds of ions $\left(\mathrm{Cl}^{-}\right.$and $\mathrm{DS}^{-}$anions) adsorbed on the surface of the sensor. When the area percentage that $\mathrm{Cl}^{-}$ions occupied is $a$, then that of the $\mathrm{DS}^{-}$ions occupied is 1-a. The adsorption of the $\mathrm{NaCl}$ and $\mathrm{SDS}$ anions on solid surface can be expressed by

$$
\Gamma_{\text {mix }}=a \cdot \Gamma_{N a C l}+(1-a) \cdot \Gamma_{S D S}
$$

where $\Gamma_{\mathrm{mix}}$ is the total adsorption capacity in the mixtures, $\Gamma_{\mathrm{NaCl}}$ and $\Gamma_{S D S}$ are the adsorptions of the $\mathrm{NaCl}$ and $\mathrm{SDS}$ anions respectively. Substituting the equilibrium adsorption capacities of the $\mathrm{NaCl}$ and SDS anions into the Equation (2), the value of $a$ is estimated to be $1 / 7$. That is so say, if there is no overlap among the different ions or molecules, the area occupied by $\mathrm{Cl}^{-}$ions is about $14 \%$ and the area occupied by DS $^{-}$anions is about $86 \%$ at the interface of the solid and liquid.

The adsorption process shown in Figure. 9 can be fit with the classical Langmuir 
adsorption isotherm model.[27, 28]

$$
\Gamma=\Gamma^{\infty} \frac{K c}{1+K c}
$$

where $\Gamma$ is the adsorption at a certain concentration, $\Gamma^{\infty}$ is the maximum adsorption at high solution concentration, $c$ is the concentration of the surfactant in the bulk solution, $K$ is a function of $c$ and the adsorbed molecules at the interface, which can be expressed by

$$
K=\frac{\theta}{c(1-\theta)}
$$

where $\theta$ means the fraction of the surface area occupied by the adsorbed molecules.

In this experiment, owing that the solution was injected by an external pump with a constant rate, the relationship between the concentration of the surfactant in the QCM testing module and the time ( $t$ ) could be expressed in Equation (5).

$$
c=A t
$$

where $A$ is a constant depended on the pumping rate of the liquid.

Substituting Equation and (5) into Equation (3), we get

$$
\Gamma=\Gamma^{\infty} \frac{K A t}{1+K A t}
$$

Equation (6) was used to fit the adsorption process from the start to equilibrium in Figures.9c and 9d, and the fitting curves were plotted in Figures.10a and 10b respectively. The blue lines are the testing results of QCM, and the red lines are the fitting curves. The parameters and related factors of the fitting curves are listed in Table 1 . The correlation coefficient $\left(R^{2}\right)$ indicates that the model fits the experimental data well. From Table 1, we can see that the saturated adsorption capacity at the $\mathrm{Al}_{2} \mathrm{O}_{3}$ surface is $223.18 \mathrm{ng} / \mathrm{cm}^{2}$ in $1 \mathrm{mM} \mathrm{SDS}$ solution and $211.78 \mathrm{ng} / \mathrm{cm}^{2}$ in the mixture of 
$1 \mathrm{mM}$ SDS and $10 \mathrm{mM} \mathrm{NaCl}$. These results also indicate that $\mathrm{Cl}^{-}$can occupy a part of the space on the $\mathrm{Al}_{2} \mathrm{O}_{3}$ surface and decrease the adsorption capacity in the mixture, comparing with $1 \mathrm{mM}$ SDS solution, which is consistent with the results in Figure.9.

Since $A$ can be regarded as a constant, $K A$ directly relates with the fraction of the surface area occupied by the adsorbed molecules $(\theta)$, according to Equation (4). Comparing the values of $K A$ for the two solutions, it can be concluded that the adsorption rate of the additives in the mixture is 2.03 times faster than that in the SDS single solution at the same pumping time.
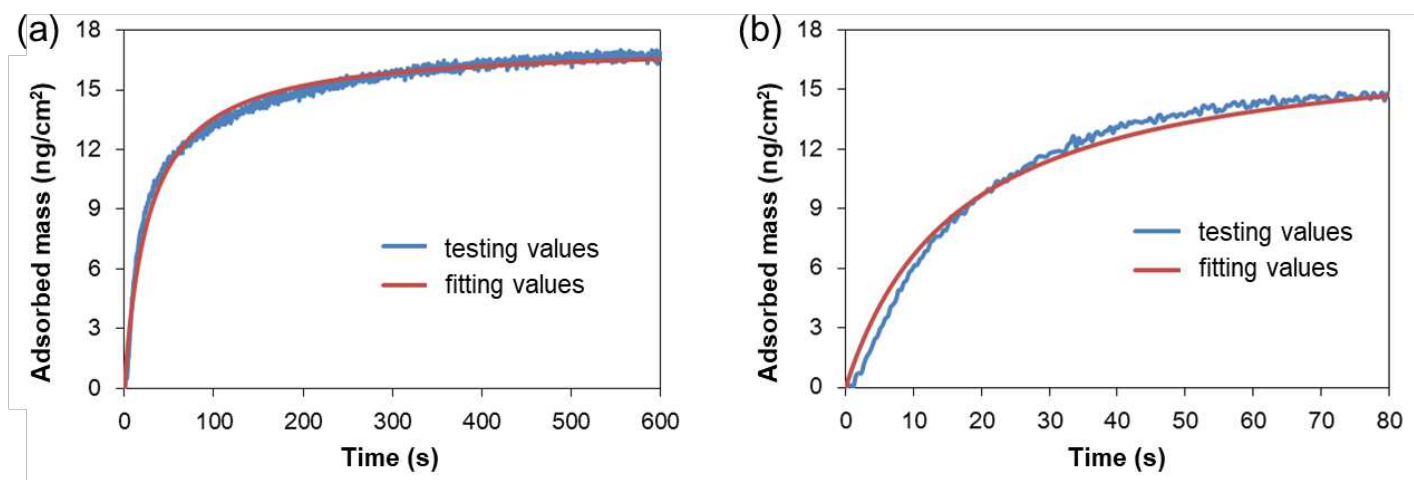

Figure.10 Experimental results measured by QCM and their fitting curves calculated by the Langmuir adsorption isotherm at the $\mathrm{Al}_{2} \mathrm{O}_{3}$ surface in different solutions, including (a) $1 \mathrm{mM}$ SDS solution and (b) the mixture solution of $1 \mathrm{mM}$ SDS and $10 \mathrm{mM} \mathrm{NaCl}$.

Table. 1 The parameters and related factors of the fitting curves for the adsorption results at $\mathrm{Al}_{2} \mathrm{O}_{3}$ surface in different solutions

\begin{tabular}{cccc}
\hline Content in aqueous solutions & $\Gamma^{\infty}$ & $K A$ & $R^{2}$ \\
\hline $1 \mathrm{mM} \mathrm{SDS}$ & $223.18 \mathrm{ng} / \mathrm{cm}^{2}$ & 0.03525 & 0.980 \\
$1 \mathrm{mM} \mathrm{SDS}+10 \mathrm{mM} \mathrm{NaCl}$ & $211.78 \mathrm{ng} / \mathrm{cm}^{2}$ & 0.07163 & 0.975 \\
\hline
\end{tabular}

\subsection{Discussions on the mechanism}

From the experiment results described above, adsorption of the $\mathrm{DS}^{-}$anions on 
the rubbing surfaces of the ceramic tribo-pairs results in formation of lubricious boundary films and thus reduction in friction coefficient, while the desorption of the $\mathrm{DS}^{-}$anions from the surfaces gives rise to rebound in friction. For the SDS surfactant solutions with relative low concentrations (lower than the critical micelle concentration, $\mathrm{CMC}$ ), the adsorption of $\mathrm{DS}^{-}$anions on solid surfaces can be expressed by

$$
\Gamma=l c \cdot \exp \left(-\frac{\Delta \bar{G}_{a d s}^{\theta}}{R T}\right)
$$

where $l$ is the effective length of the anion chain, $c$ is the bulk concentration of the anions, $R$ is the gas constant, $T$ is the absolute temperature and $\Delta \bar{G}_{\text {ads }}^{\theta}$ is the standard free energy of adsorption. Generally, $\Delta \bar{G}_{a d s}^{\theta}$ includes the contributions from electrostatic interactions ( $\Delta G_{\text {elec }}$ ), chemical interactions, hydrophobic lateral interactions, hydrophobic interaction between the hydrocarbon chains and hydrophobic sites on the solid, hydrogen bonding and dissolving energy.[28] For the tribosystem shown in Figure.1, $\Delta G_{\text {elec }}$ is negligible, because $\mathrm{Al}_{2} \mathrm{O}_{3}$ and $\mathrm{ZrO}_{2}$ surfaces in aqueous solutions with $\mathrm{pH}$ value of $6-8$ are electrically neutral[30, 31]. It is not affected by the presence of an electric field on the working and counter electrodes neither. However, the local concentration of $\mathrm{DS}^{-}$anions, $c$, around the contact point depends on the charging state of the steel holder (i.e. working electrode). When the working electrode is positively charged, more $\mathrm{DS}^{-}$anions are attracted towards the contact area as shown in Figure.11b and vice versa as shown in Figure.11c, comparing to the uncharged state shown in Figure.11a. This makes the adsorption amount of DS anions, $\Gamma$, tunable by the electric field applied on the steel ball holder. Therefore, it 
can be regarded as an indirect tunable adsorption approach. If one part of a tribo-pair is conductive and serves as the working electrode, the electrostatic interaction predominates the standard free energy of adsorption, as shown in Equation (8).

$$
\Delta \bar{G}_{a d s}^{\vartheta} \approx \Delta G_{e l e c}=-z F \psi_{\delta}
$$

where $z$ is the valency of the adsorbate species, $F$ is the Faraday constant and $\psi_{\delta}$ is the electric potential.[28] Thereby, tuning $\psi_{\delta}$ can directly change the adsorption capacity of ions at the solid-liquid interface. This can be referred as direct tuning adsorption approach, which has been reported previously.[29] Comparing between the two approaches, the advantage of the indirect approach is no requirement for the conductivity of friction pairs and hence applicable to both conductors and insulators, while the direct approach has a quicker response.

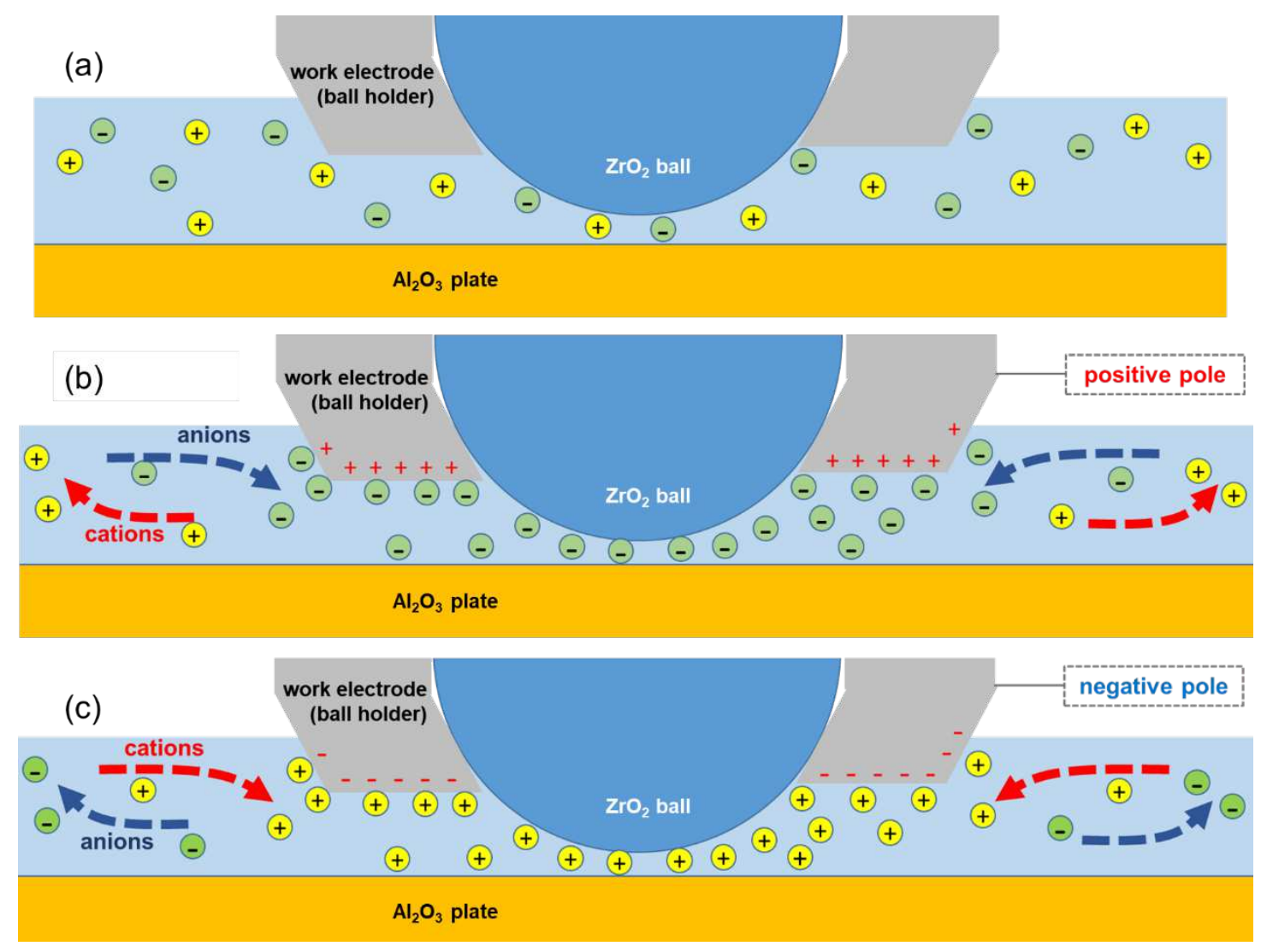


Figure.11 Schematic illustrations of the active control friction between ceramics. (a) Presence of ions in solution in the absence of applied voltage without consideration of the double electric layer at the solid-liquid interface, (b) anions (such as $\mathrm{DS}^{-}$) accumulate near the contact area when the positive surface potential of the working electrode is applied, and (c) cations ( such as $\mathrm{Na}^{+}$) accumulate near the contact area when the negative surface potential of the working electrode is applied.

According to colloid science, when an inorganic salt is added to the SDS solution, the increase of counterions reduces the electrostatic repulsion between the $\mathrm{DS}^{-}$ions and compresses the double electric layer, tending the formation of SDS micelles. The relationship between the concentration of counterions and the CMC can be expressed by Equation (9).[32]

$$
\ln (\mathrm{CMC})=\mathrm{a}_{1}-\mathrm{a}_{2} \cdot \ln \left(\mathrm{c}_{\mathrm{i}}\right)
$$

where $a_{1}$ and $a_{2}$ are constants for a given ionic head group at a particular temperature and $c_{i}$ is the total concentration of counterion $\left(\mathrm{Na}^{+}\right.$in this work). The equation tells us that the CMC of SDS solutions lowers as $\mathrm{Na}^{+}$concentration increases. The schematic diagrams of the ions in SDS solutions without or with $\mathrm{NaCl}$ are shown in Figure.12. When SDS concentration is lower than the CMC, isolated ions distribute in the solution (Figure.12a). Figure.12b presents the state of ions in the mixture solution of $1 \mathrm{mM} \mathrm{SDS}$ and $10 \mathrm{mM} \mathrm{NaCl}$. Due to the presence of $\mathrm{NaCl}$, the concentration of $\mathrm{Na}^{+}$in the solution increases from $1 \mathrm{mM}$ (by the dissociation of SDS) to $10 \mathrm{mM}$ (by the dissociation of SDS and $\mathrm{NaCl}$ ). Therefore, more counterions can adsorb on the surface of DS- $^{-}$ions as well as their aggregations by the electrostatic interaction, causing the formation of micelles in relatively lower concentration of the SDS. Zhang et al has studied the effect of concentration and addition of ions on the 
adsorption of SDS on stainless steel surface in aqueous solutions in 2015.[25] The result in this work agrees well with their conclusion that adsorption isotherm shifts to lower SDS concentration regime with added $\mathrm{Na}^{+}$salts.

In addition, a double electric layer exists at the interface between a micelle and its liquid medium as shown in Figure.12b, which consists of two parts, including an inner region where the ions bound relatively tightly to the surface, and an outer region where the balance of electrostatic forces and random thermal motion determines the ion distribution. When the micelle moves, ions within the boundary move. While, the ions in the outer region stay with the bulk dispersant. The potential at this boundary (slipping plane) is defined as zeta potential, which has been described in the above analysis.

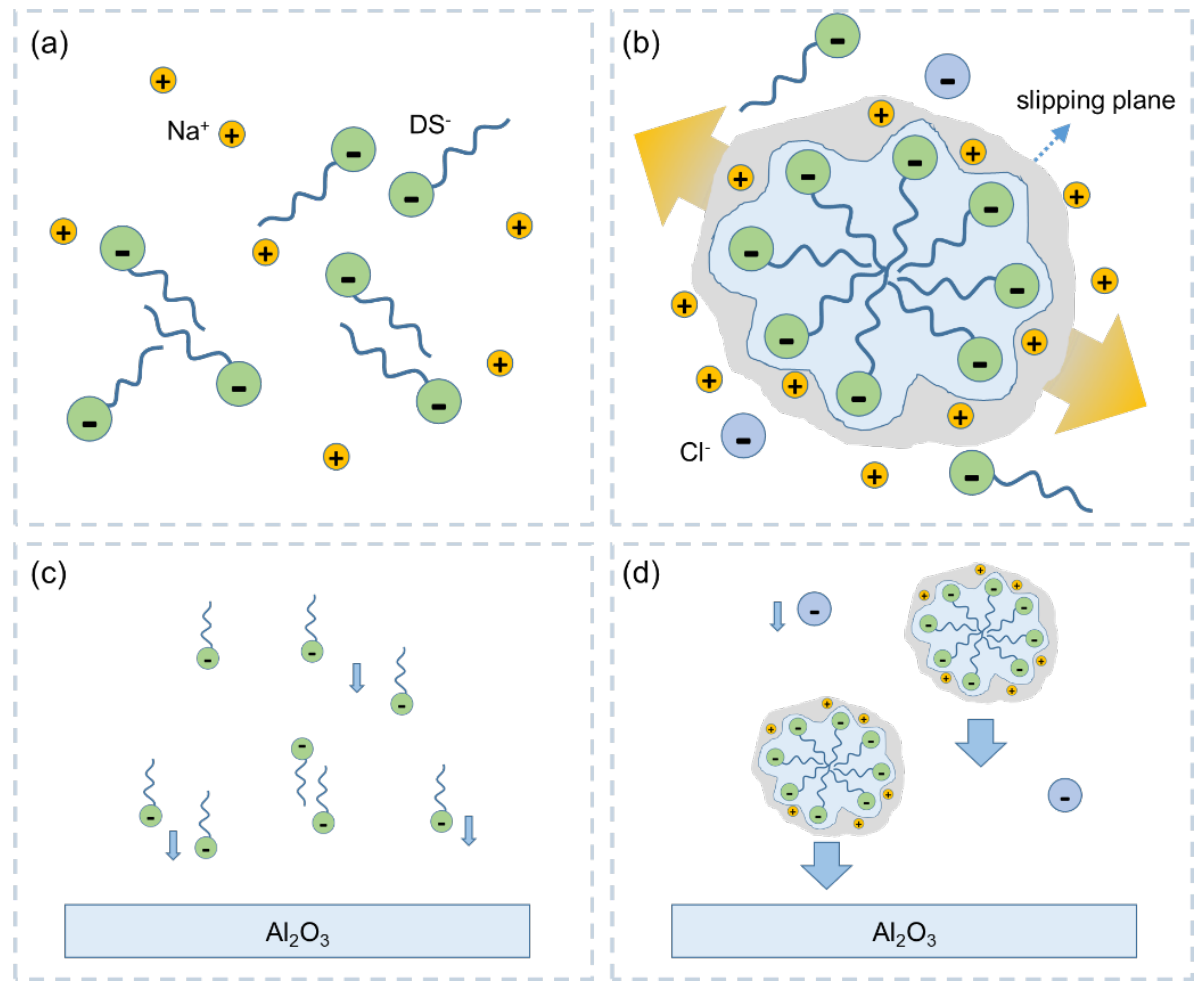

Figure.12 Schematic diagram of the $\mathrm{DS}^{-}$and $\mathrm{Na}^{+}$in different conditions. (a) in the bulk phase of $1 \mathrm{mM}$ SDS solution, (b) in the bulk phase of the mixed solution of $1 \mathrm{mM}$ SDS 
and $10 \mathrm{mM} \mathrm{NaCl}$, (c) at the interface of the $\mathrm{Al}_{2} \mathrm{O}_{3}$ solid and $1 \mathrm{mM}$ SDS solution and (d) at the interface of the $\mathrm{Al}_{2} \mathrm{O}_{3}$ solid and the mixed solution of $1 \mathrm{mM} \mathrm{SDS}$ and $10 \mathrm{mM} \mathrm{NaCl}$.

From the adsorption isotherm shown in Figures.10a and 10b, we can see that the process of the solitary DS ${ }^{-}$ions from starting adsorption to adsorption equilibrium on the solid surface is relatively slower in SDS solution than that of the SDS micelles in the mixture solution. The phenomenon can be explained with the schematic diagram of the $\mathrm{DS}^{-}$and $\mathrm{Na}^{+}$in the above two solutions shown in Figures.12c and 12d, respectively. The transportation rate of micelles from the interior of solutions toward solid surfaces is faster than that of isolated ions. This is also true for the desorption process. Therefore, addition of $\mathrm{NaCl}$ salt improves the response of adsorption/desorption as well as friction to the changes in surface potentials.

From the adsorption isotherm shown in Figure.9d, we can see that the maximal adsorption capacity reaches $193 \mathrm{ng} / \mathrm{cm}^{2}$ at about $270 \mathrm{~s}$, and then decreases to a relatively stable value of $180 \mathrm{ng} / \mathrm{cm}^{2}$ after $360 \mathrm{~s}$. A similar process occurs during the desorption process. This phenomenon is considered to be caused by the phase transition process after the first adsorption equilibrium. $[33,34]$ That is to say, when micelles just arrive at the interface, the entirety adsorption is carried out firstly, which increases the adsorption capacity rapidly. Then, it takes tens of seconds for the micelles to be self-assembled at the interface under the electrostatic and hydrophobic interactions. During the process, the dissipation factor also shows a relatively significant changes, as shown in Figure.9a. This result also indicates that in the mixture solution of $1 \mathrm{mM}$ SDS and $10 \mathrm{mM} \mathrm{NaCl}$, the state of adsorbents at the solid- 
liquid interface is micelle, rather than solitary DS- ions or SDS molecules.

\section{Conclusions}

Through a proper design of electrode cell, active control of the friction between $\mathrm{ZrO}_{2}$ ball and the $\mathrm{Al}_{2} \mathrm{O}_{3}$ plate in water-based lubrication has been realized by applying an external electric field. The COF can be varied reversely with the applied electric field in the range of 0.12 to 0.35 . The addition of inorganic salts containing counterions to the surfactant solution can shorten the response time by facilitating the formation of SDS anions into micelles. Moreover, an indirect adsorption model has been proposed based the classical adsorption theory. When one of the electrodes is near the contact area of the friction pairs, the applied electric field can change the distribution of the concentration of the surfactant SDS. As a result, the adsorption behavior of the SDS at the interface between the friction pairs can be controlled indirectly, which can influence the tribological behaviors of the system significantly. This work has demonstrated a novel method to realize the active control of friction for the water-based lubricants with ceramics working as friction pairs, and also deepened the understanding of boundary lubrication.

\section{Conflicts of interest}

There are no conflicts to declare. 


\section{Acknowledgements}

This work has been financially supported by National Natural Science Foundation of

China (Grant Nos. 51961145303, 51635009) and the Chinese National Key R\&D Plan

(Grant No. 2016YFE0130300).

\section{References}

[1] Sliney H.E., DellaCorte C. The Friction and Wear of Ceramic/ Ceramic and Ceramic/Metal Combinations in Sliding Contact. STLE-ASME. New Orleans, LA: (1993).

[2] Gahr K.H.Z.: Sliding wear of ceramic-ceramic, ceramic-steel and steel-steel pairs in lubricated and unlubricated contact. Wear. 133. 1 (1989).

[3] Bartelt G.: Sliding Friction and Wear of Ceramic/Ceramic Couples Lubricated with Hexadecane. Tribology Series. 30. 635 (1995).

[4] Aronov V., Mesyef T.: Wear in Ceramic/Ceramic and Ceramic/Metal Reciprocating Sliding Contact. Part 1. Journal of Tribology. 108. 16 (1986).

[5] Bernhardt J., Albers A., Ott S.: Advanced ceramics as friction material in lubricated clutch systems. Tribology International. 59. 267 (2013).

[6] Çilingir A.Ç., Uçar V., Çallı I.: Comparison of Different Bearing Couples of Hip Resurfacing Prostheses: A Finite Element Study. Applied Mechanics and Materials. 110-116. 904 (2011).

[7] Yamamoto T., Ito H., Niizeki S., Matsunaga S.: Rolling Life Properties of Ceramic Bearings in Water. Key Engineering Materials. 317-318. 359 (2006).

[8] Amutha Rani D., Yoshizawa Y., Hyuga H., Hirao K., Yamauchi Y.: Tribological behavior of ceramic materials ( $\mathrm{Si} 3 \mathrm{~N} 4, \mathrm{SiC}$ and $\mathrm{Al2O} 3$ ) in aqueous medium. Journal of the European Ceramic Society. 24.3279 (2004).

[9] Roldo L., Komar I., Vulić N.: Design and Materials Selection for Environmentally Friendly Ship Propulsion System. Strojniški vestnik - Journal of Mechanical Engineering. 59. 25 (2013).

[10] Nunes D.G., Da Silva A.D.P.M., Cajaiba J., Pérez-Gramatges A., Lachter E.R., Nascimento R.S.V.: Influence of glycerides-xanthan gum synergy on their performance as lubricants for water-based drilling fluids. Journal of Applied Polymer Science. 131. n/a-n/a (2014).

[11] Zhang J., Meng Y.: Stick - Slip Friction of Stainless Steel in Sodium Dodecyl Sulfate Aqueous Solution in the Boundary Lubrication Regime. Tribology Letters. 56.543 (2014).

[12] Peng Y., Hu Y., Wang H.: Tribological behaviors of surfactant-functionalized carbon nanotubes as lubricant additive in water. Tribology Letters. 25.247 (2007).

[13] Jia W., Tian J., Bai P., Li S., Zeng H., Zhang W., Tian Y.: A novel comb-typed poly(oligo(ethylene glycol) methylether acrylate) as an excellent aqueous lubricant. Journal of Colloid and Interface Science. 539. 342 (2019).

[14] Li J., Zhang C., Deng M., Luo J.: Investigations of the superlubricity of sapphire against ruby under phosphoric acid lubrication. Friction. 2. 164 (2014).

[15] Han T., Zhang C., Chen X., Li J., Wang W., Luo J.: Contribution of a Tribo-Induced Silica Layer to Macroscale Superlubricity of Hydrated Ions. The Journal of Physical Chemistry C. 123. 20270 
(2019).

[16] Zhang S., Zhang C., Hu Y., Ma L.: Numerical simulation of mixed lubrication considering surface forces. Tribology International. 140. 105878 (2019).

[17] Yonggang M., Chenxu L. Spatiotemporal manipulation of boundary lubrication by electro-charging and electrochemical methods. In: Erdemir A., Martin J.M., Luo J. Superlubricity (Second Edition). Elsevier, 499 (2021).

[18] He S., Meng Y., Tian Y., Zuo Y.: Response Characteristics of the Potential-Controlled Friction of $\mathrm{ZrO}_{2} /$ Stainless Steel Tribopairs in Sodium Dodecyl Sulfate Aqueous Solutions. Tribology Letters. 38. 169 (2010).

[19] Yang X., Meng Y., Tian Y.: Effect of Imidazolium Ionic Liquid Additives on Lubrication Performance of Propylene Carbonate under Different Electrical Potentials. Tribology Letters. 56. 161 (2014).

[20] Liu C., Meng Y., Tian Y.: Potential-Controlled Boundary Lubrication Using $\mathrm{MoS}_{2}$ Additives in Diethyl Succinate. Tribology Letters. 68. (2020).

[21] Liu C., Friedman O., Meng Y., Tian Y., Golan Y.: CuS Nanoparticle Additives for Enhanced Ester Lubricant Performance. ACS Applied Nano Materials. 1. 7060 (2018).

[22] He S., Meng Y., Tian Y.: Correlation Between Adsorption/Desorption of Surfactant and Change in Friction of Stainless Steel in Aqueous Solutions Under Different Electrode Potentials. Tribology Letters. 41.485 (2011).

[23] Jiang H., Meng Y., Wen S., Ji H.: Effects of external electric fields on frictional behaviors of three kinds of ceramic/metal rubbing couples. Tribology international. 32. 161 (1999).

[24] Chang Q., Meng Y., Wen S.: Influence of interfacial potential on the tribological behavior of brass/silicon dioxide rubbing couple. Applied Surface Science. 202. 120 (2002).

[25] Zhang J., Meng Y., Tian Y., Zhang X.: Effect of concentration and addition of ions on the adsorption of sodium dodecyl sulfate on stainless steel surface in aqueous solutions. Colloids and Surfaces A: Physicochemical and Engineering Aspects. 484. 408 (2015).

[26] Thavorn J., Hamon J.J., Kitiyanan B., Striolo A., Grady B.P.: Competitive Surfactant Adsorption of AOT and TWEEN 20 on Gold Measured Using a Quartz Crystal Microbalance with Dissipation. Langmuir. 30. 11031 (2014).

[27] Guo X., Wang J.: Comparison of linearization methods for modeling the Langmuir adsorption isotherm. Journal of Molecular Liquids. 296. 111850 (2019).

[28] Zhang R., Somasundaran P.: Advances in adsorption of surfactants and their mixtures at solid/solution interfaces. Advances in Colloid and Interface Science. 123-126. 213 (2006).

[29] Zhang J., Meng Y.: Boundary lubrication by adsorption film, Friction, 3.115 (2015).

[30] Piontek S.M., Tuladhar A., Marshall T., Borguet E.: Monovalent and Divalent Cations at the $a-$ $\mathrm{Al}_{2} \mathrm{O}_{3}(0001) /$ Water Interface: How Cation Identity Affects Interfacial Ordering and Vibrational Dynamics. The Journal of Physical Chemistry C. 123. 18315 (2019).

[31] Cai Q., Lopez-Ruiz J.A., Cooper A.R., Wang J., Albrecht K.O., Mei D.: Aqueous-Phase Acetic Acid Ketonization over Monoclinic Zirconia. ACS Catalysis. 8. 488 (2017).

[32] Myers D.: Surfaces, Interfaces, and Colloids: Principles and Applications (Second Edition). WileyVCH: (1999)

[33] Kojima T.: Combined Reflectometric Interference Spectroscopy and Quartz Crystal Microbalance Detect Differential Adsorption of Lipid Vesicles with Different Phase Transition Temperatures on 
$\mathrm{SiO}_{2}, \mathrm{TiO}_{2}$, and Au Surfaces. Analytical Chemistry. 89. 13596 (2017).

[34] Kleinschmidt J.H.: Lipid-Protein Interactions. Humana Press: (2003) 


\section{Figures}

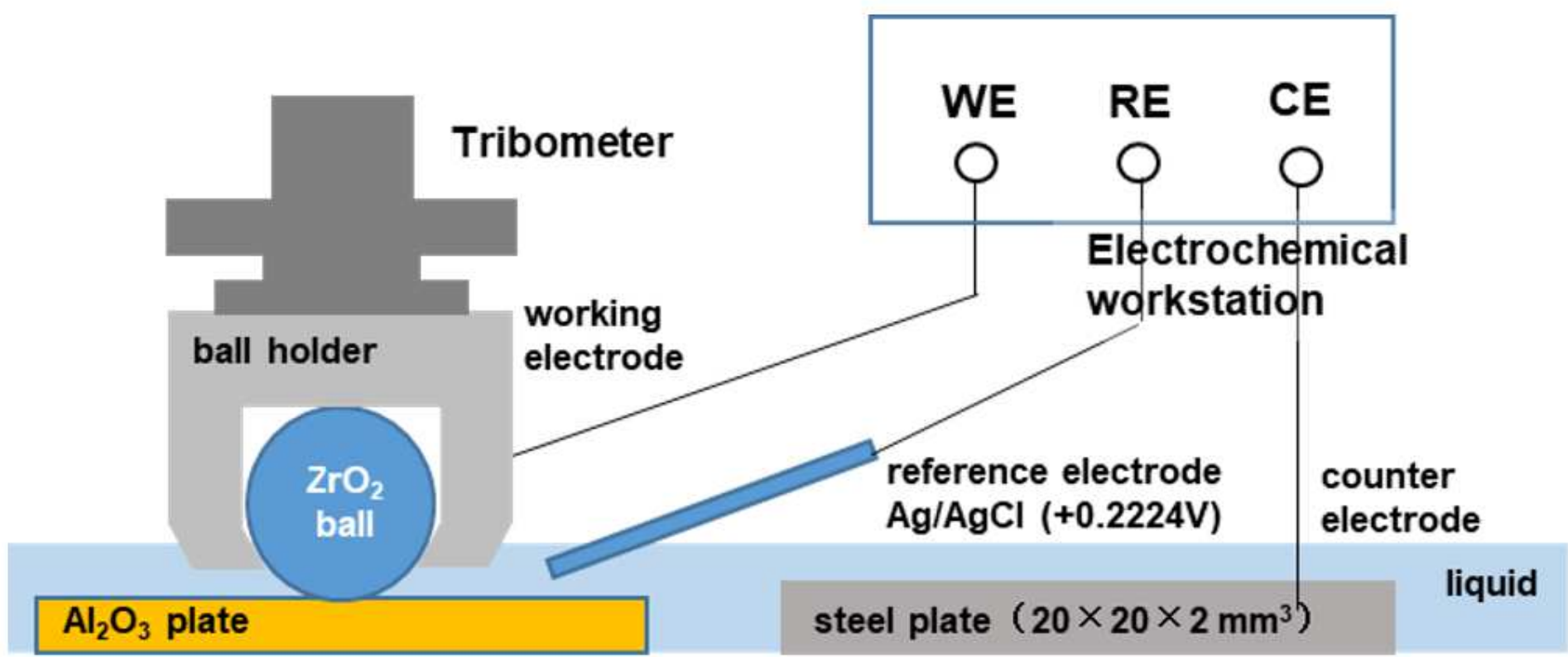

Figure 1

Schematic diagram of the testing module combining an electrochemical workstation (or a DC power supply) and a tribometer

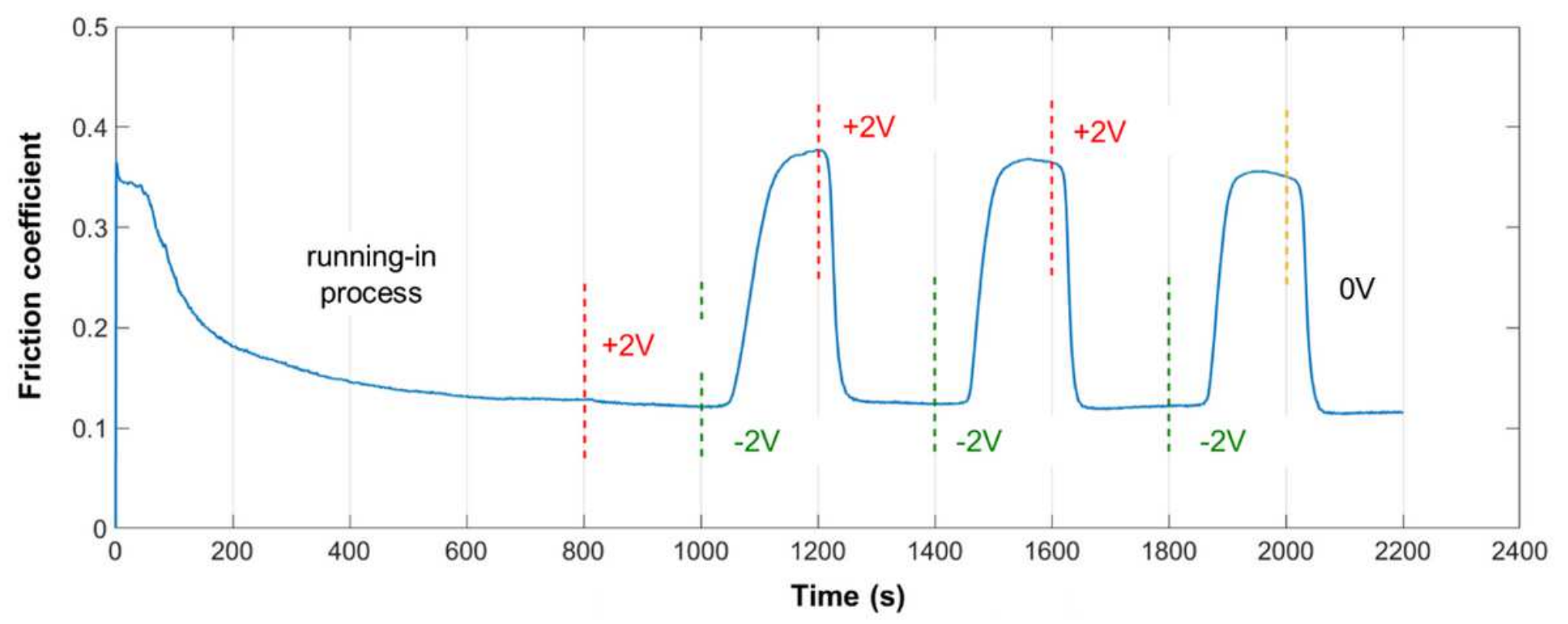

Figure 2

Friction coefficient of the Al2O3 plate vs. ZrO2 ball versus time with the mixed solution of $1 \mathrm{mM}$ SDS and $10 \mathrm{mM} \mathrm{NaCl}$ working as the lubricant under different applied potentials in two-electrode system. 


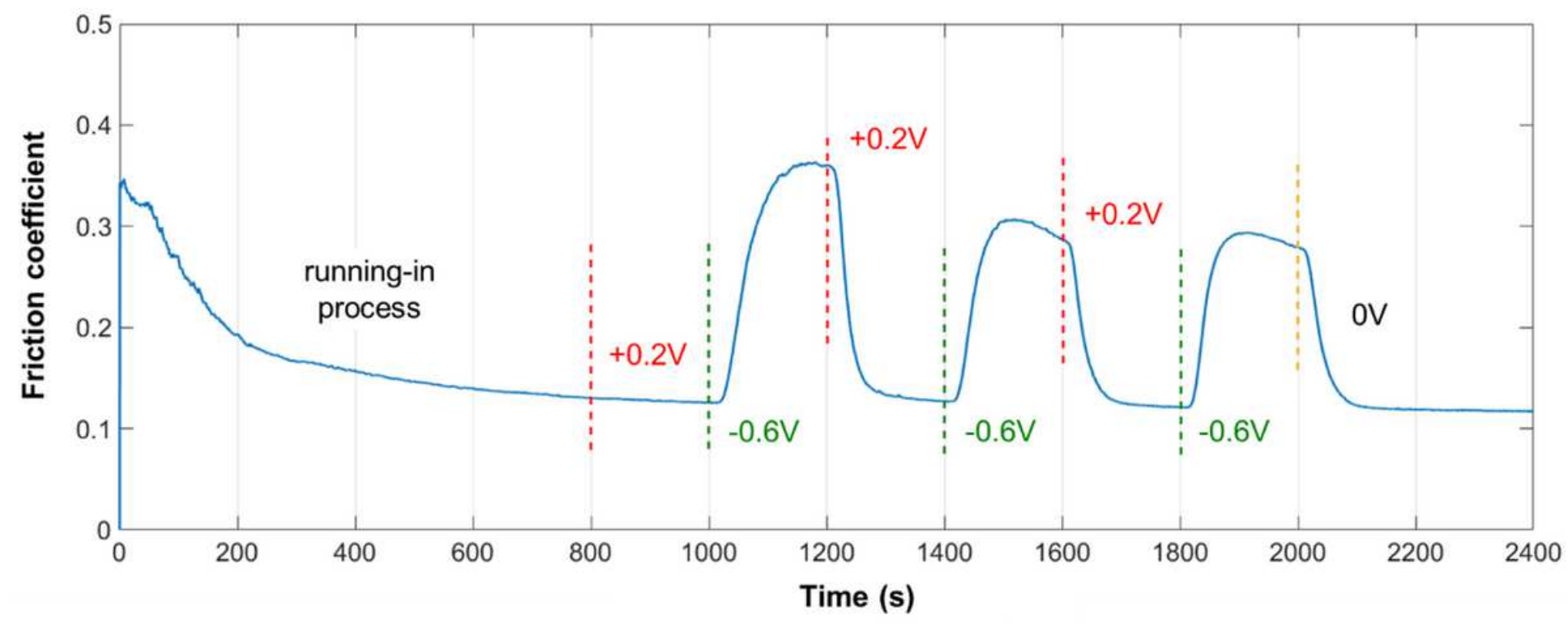

Figure 3

Friction coefficient of the Al2O3 plate vs. ZrO2 ball versus time with the mixed solution of $1 \mathrm{mM}$ SDS and $10 \mathrm{mM} \mathrm{NaCl}$ working as the lubricant under different applied surface potentials of the working electrode near the contact area in three-electrode system.

(a)
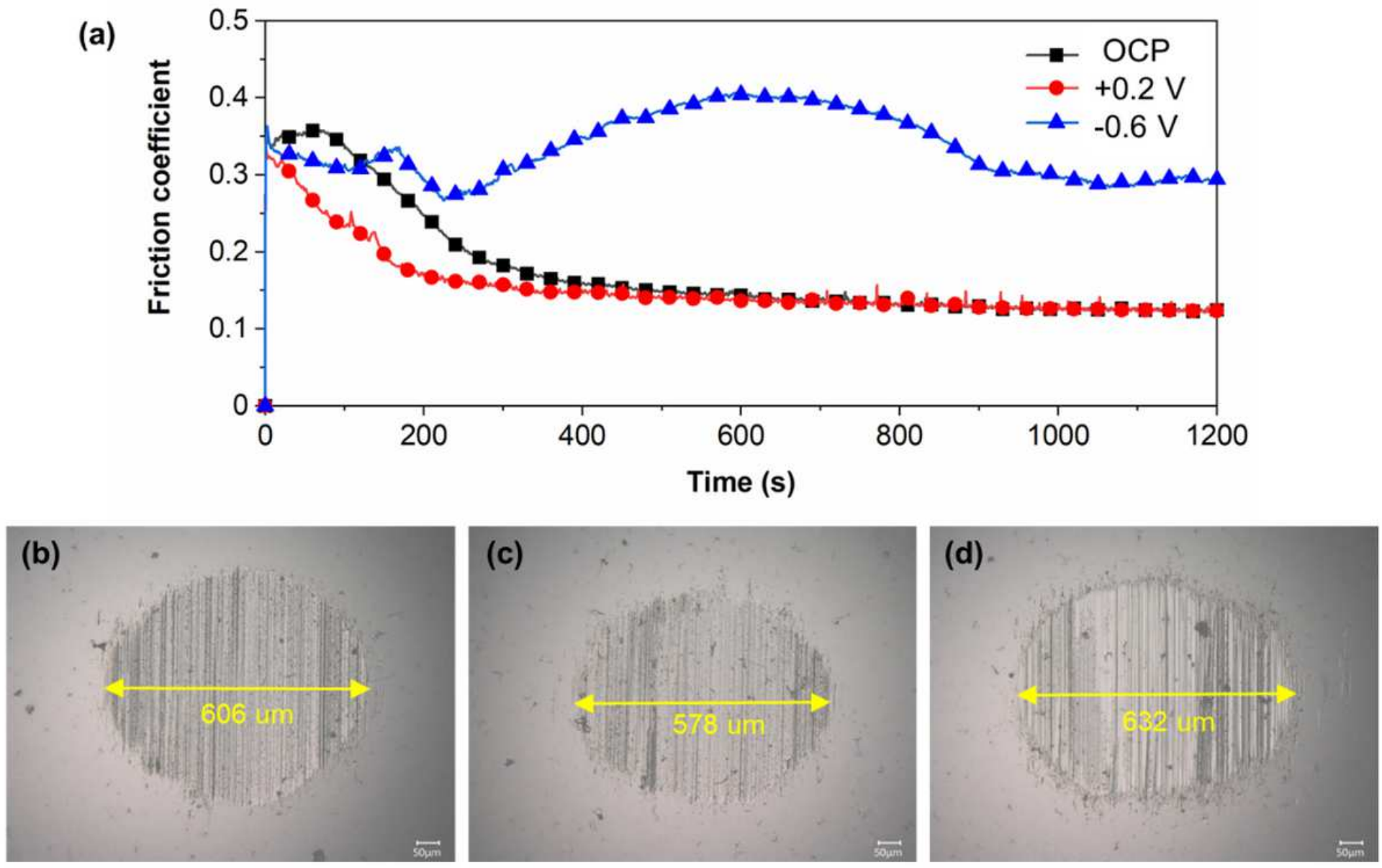

Figure 4 
Friction coefficients of the $\mathrm{ZrO} 2$ ball vs. Al2O3 plate under boundary lubrication in the mixed solution of 1 $\mathrm{mM} \mathrm{SDS}$ and $10 \mathrm{mM} \mathrm{NaCl}$ under different applied surface potentials (a), and micrographs of the wear scars on the top of the ZrO2 balls under OCP (b), positive potential of $+0.2 \mathrm{~V}(\mathrm{c})$ and negative potential of $-0.6 \mathrm{~V}(\mathrm{~d})$ for the working electrode.
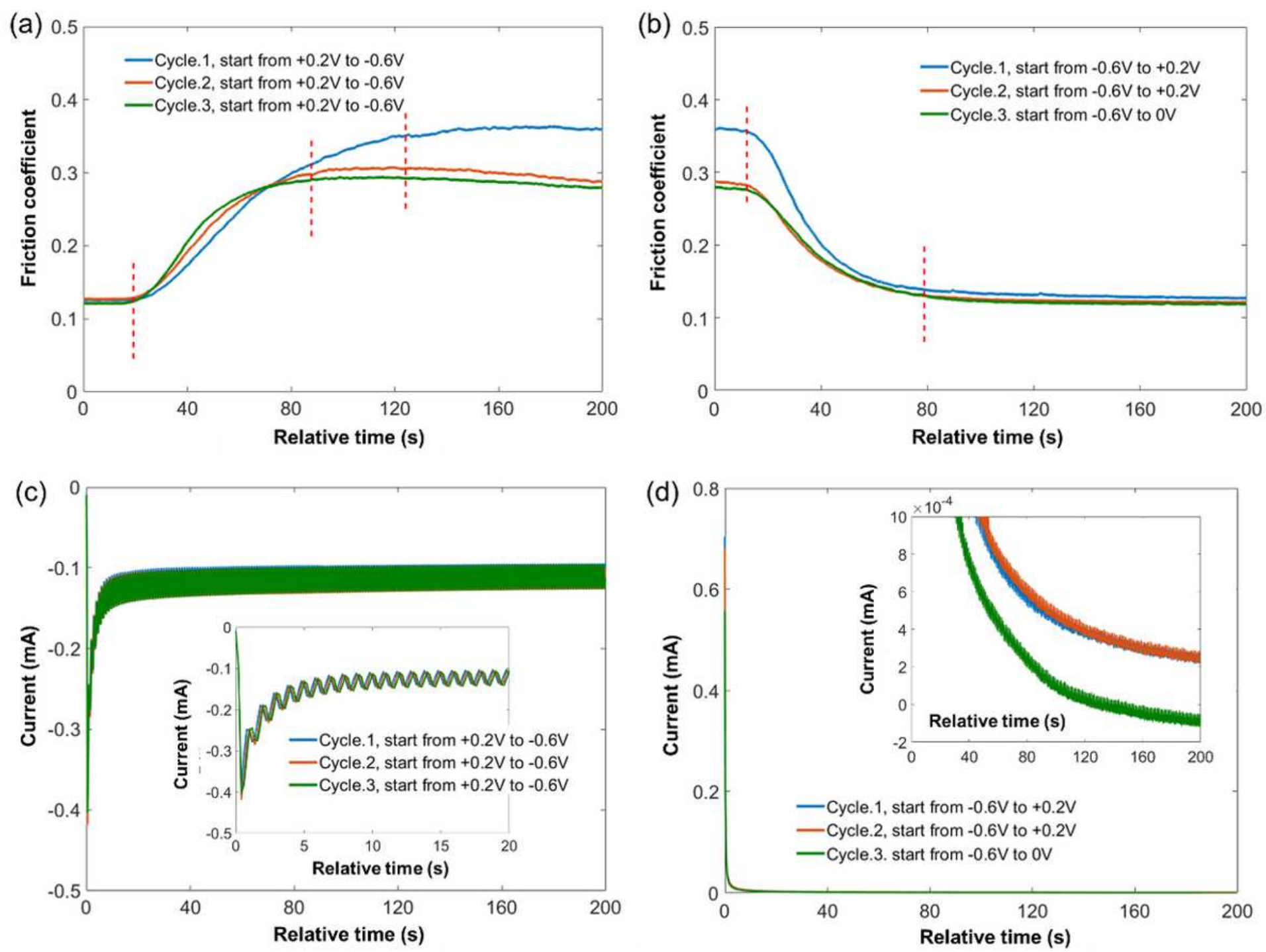

\section{Figure 5}

Relationship between the COF, electric current and time, when the surface potential was controlled and changed by electrochemical workstation. The COF over time when the surface potential was changed from $+0.2 \mathrm{~V}$ to $-0.6 \mathrm{~V}$ at $0 \mathrm{~s}$ shown in (a) and from $-0.6 \mathrm{~V}$ to $+0.2 \mathrm{~V}$ or $0 \mathrm{~V}$ at $0 \mathrm{~s}$ shown in (b). The current over time when the surface potential was changed from $+0.2 \mathrm{~V}$ to $-0.6 \mathrm{~V}$ at $0 \mathrm{~s}$ shown in (c) and from -0.6 $\mathrm{V}$ to $+0.2 \mathrm{~V}$ or $0 \mathrm{~V}$ at $0 \mathrm{~s}$ shown in (d). 


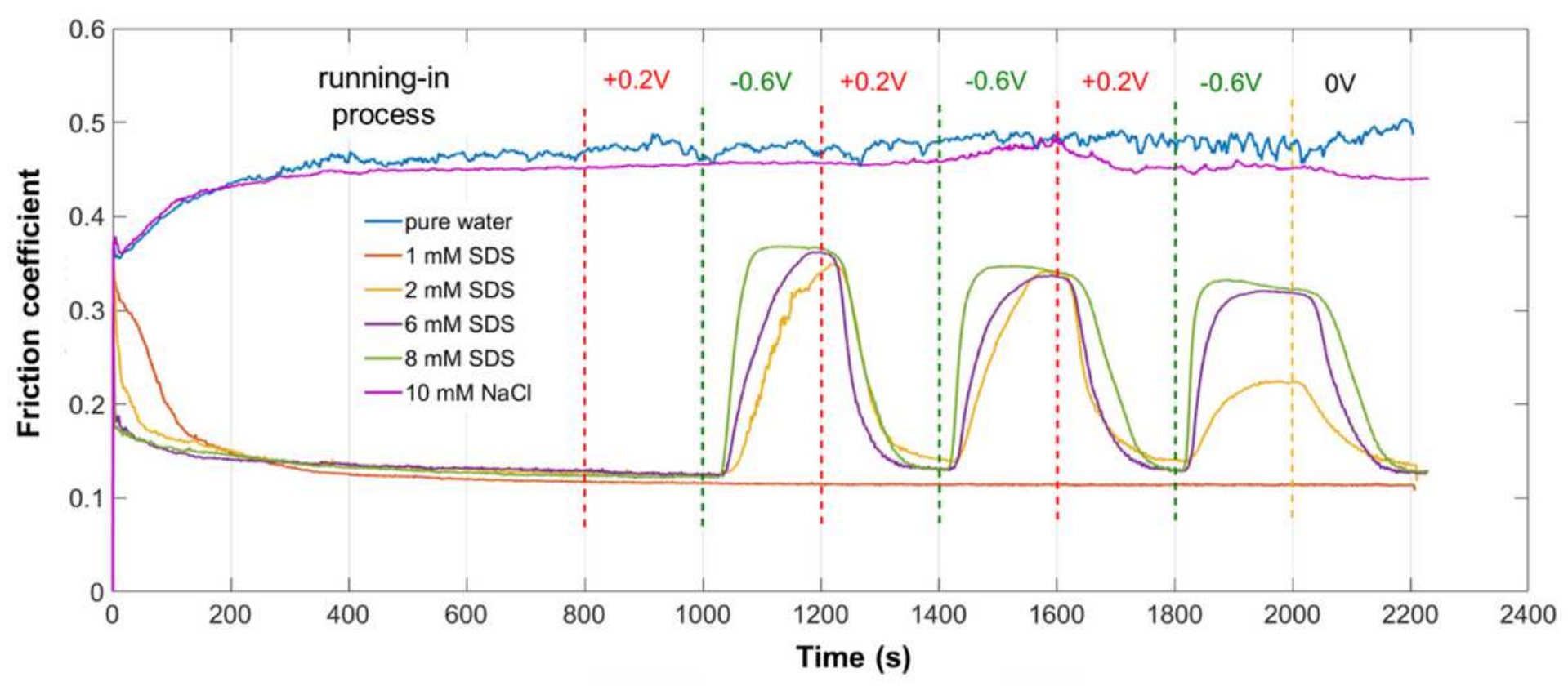

\section{Figure 6}

Friction coefficient of the $\mathrm{Al} 2 \mathrm{O} 3$ plate vs. $\mathrm{ZrO} 2$ ball versus time with pure $\mathrm{H} 2 \mathrm{O}$ or single solution working as the lubricant under different applied potentials of the working electrode near the contact area.

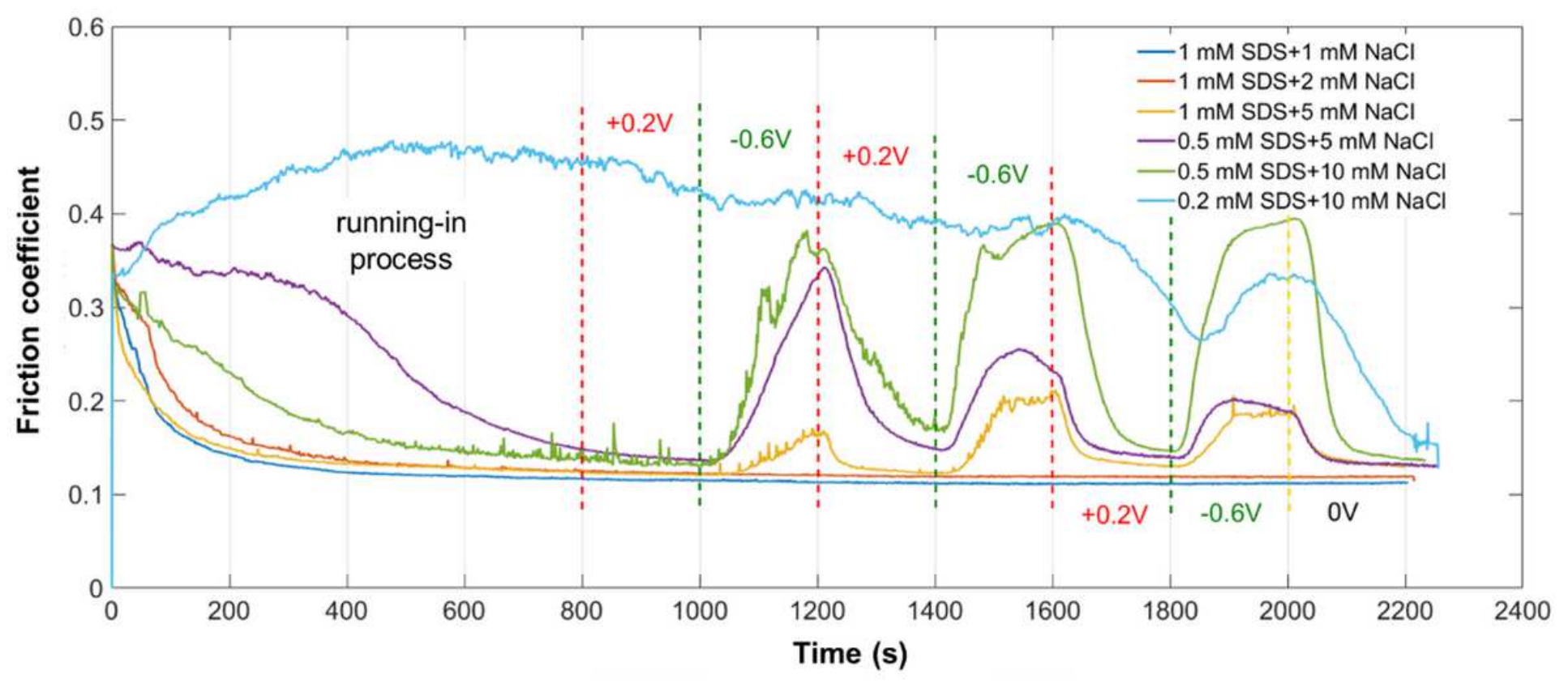

Figure 7

Friction coefficient of Al2O3 plate vs. $\mathrm{ZrO} 2$ ball over time in the mixed solutions with different contents of SDS and $\mathrm{NaCl}$ under different applied potentials of the working electrode near the contact area. 

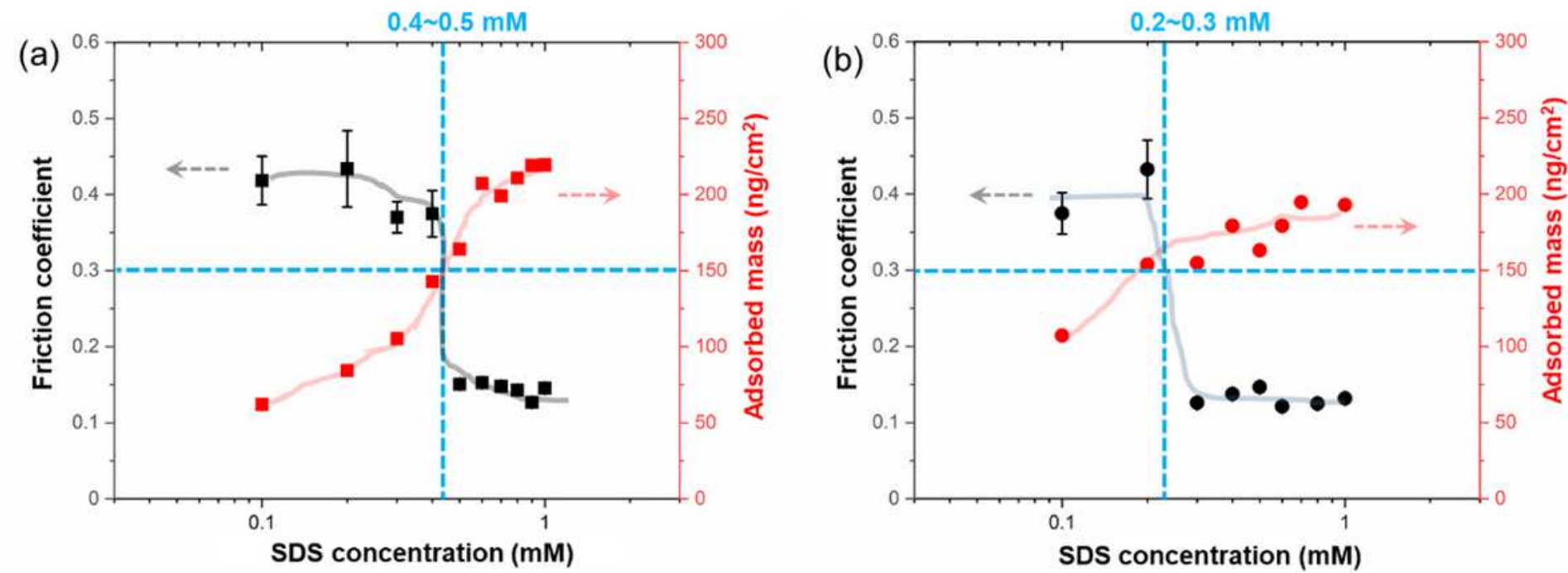

Figure 8

Friction coefficient and adsorption behaviors for the solutions with different SDS concentrations in the absence (a) and the presence of $10 \mathrm{mM} \mathrm{NaCl}(\mathrm{b})$.
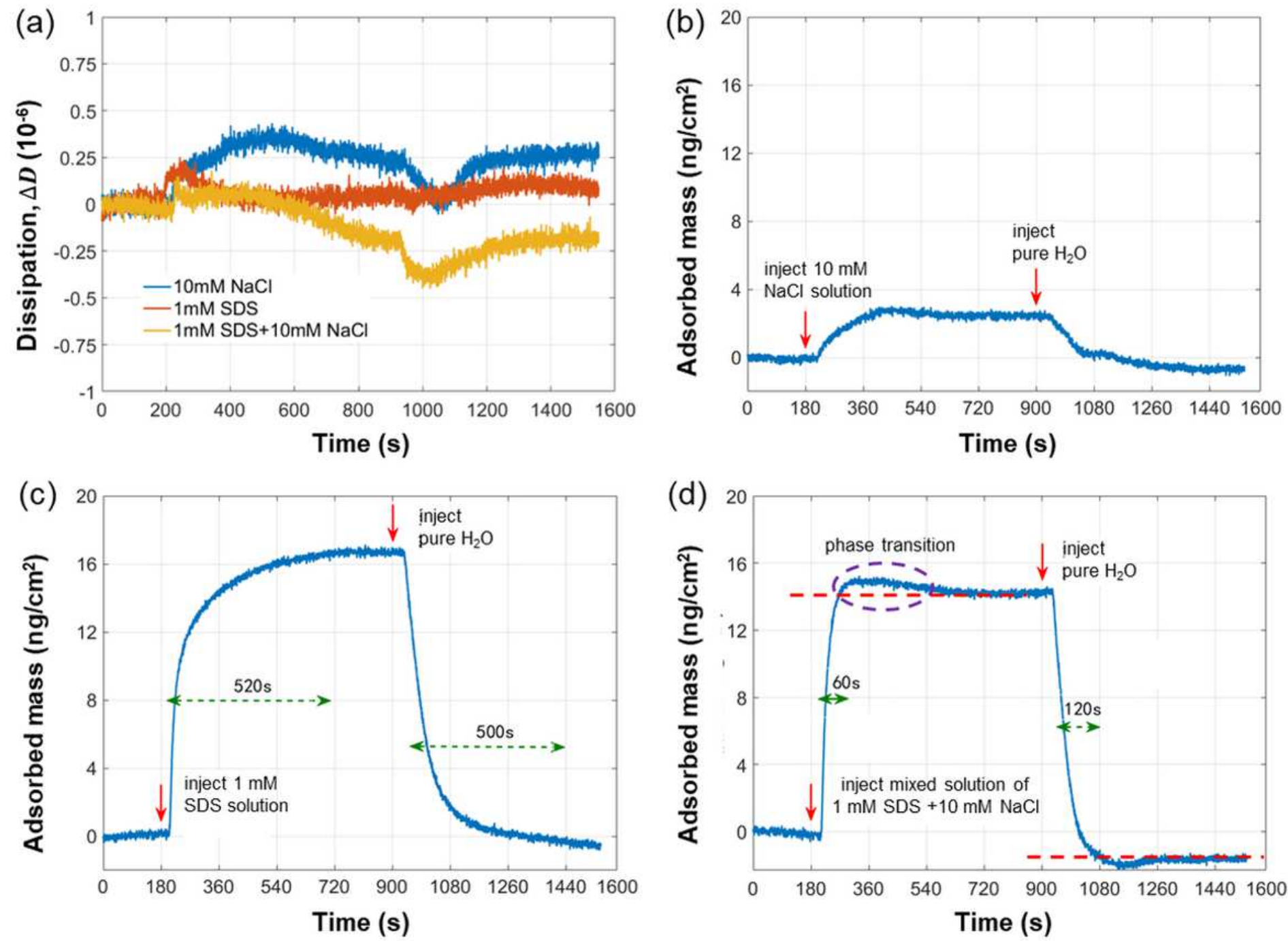


\section{Figure 9}

Adsorption behaviors of the additives in three different solutions by QCM, including the variation of dissipation factors with time in different solutions (a) and the curves of adsorption capacity and time in different solutions of $10 \mathrm{mM} \mathrm{NaCl}$ (b), $1 \mathrm{mM} \mathrm{SDS} \mathrm{(c)} \mathrm{and} 1 \mathrm{mM} \mathrm{SDS}+10 \mathrm{mM} \mathrm{NaCl}$ (d). All of the above results were obtained when pure $\mathrm{H} 2 \mathrm{O}$ was tested to be the base line, then the solution was injected at 180 $s$ for the adsorption tests, and finally the pure $\mathrm{H} 20$ was injected at $900 \mathrm{~s}$ for the desorption testing. The test temperature was held at $25^{\circ} \mathrm{C}$.
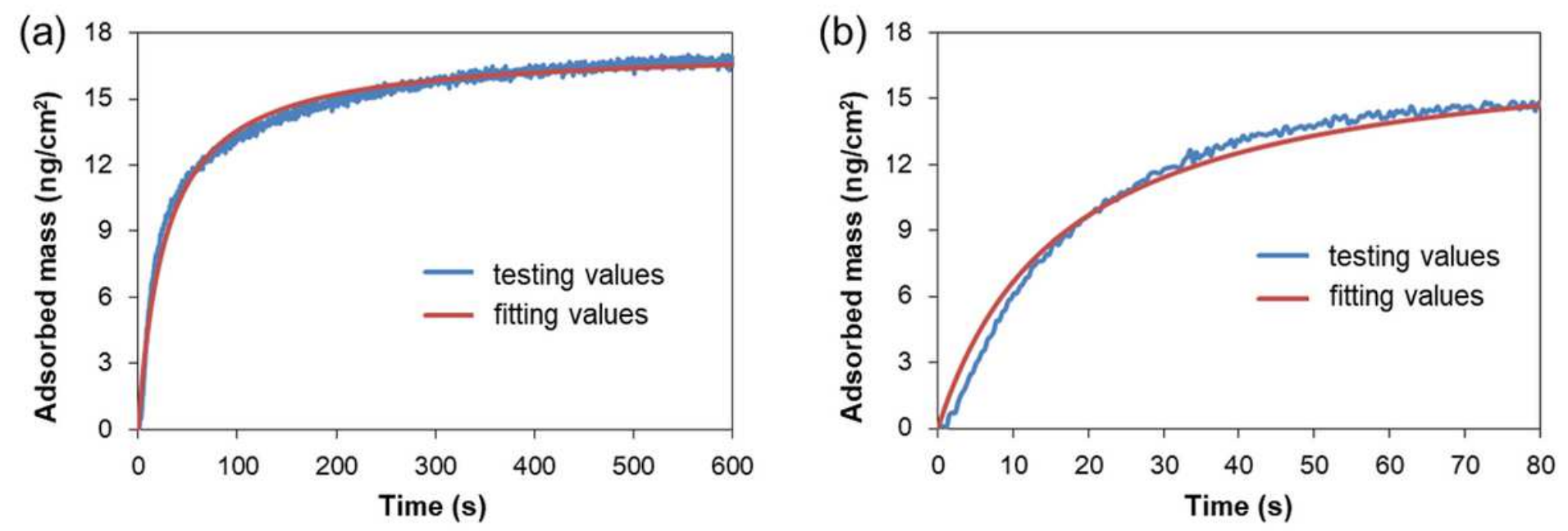

\section{Figure 10}

Experimental results measured by QCM and their fitting curves calculated by the Langmuir adsorption isotherm at the Al2O3 surface in different solutions, including (a) $1 \mathrm{mM}$ SDS solution and (b) the mixture solution of $1 \mathrm{mM} \mathrm{SDS}$ and $10 \mathrm{mM} \mathrm{NaCl}$. 

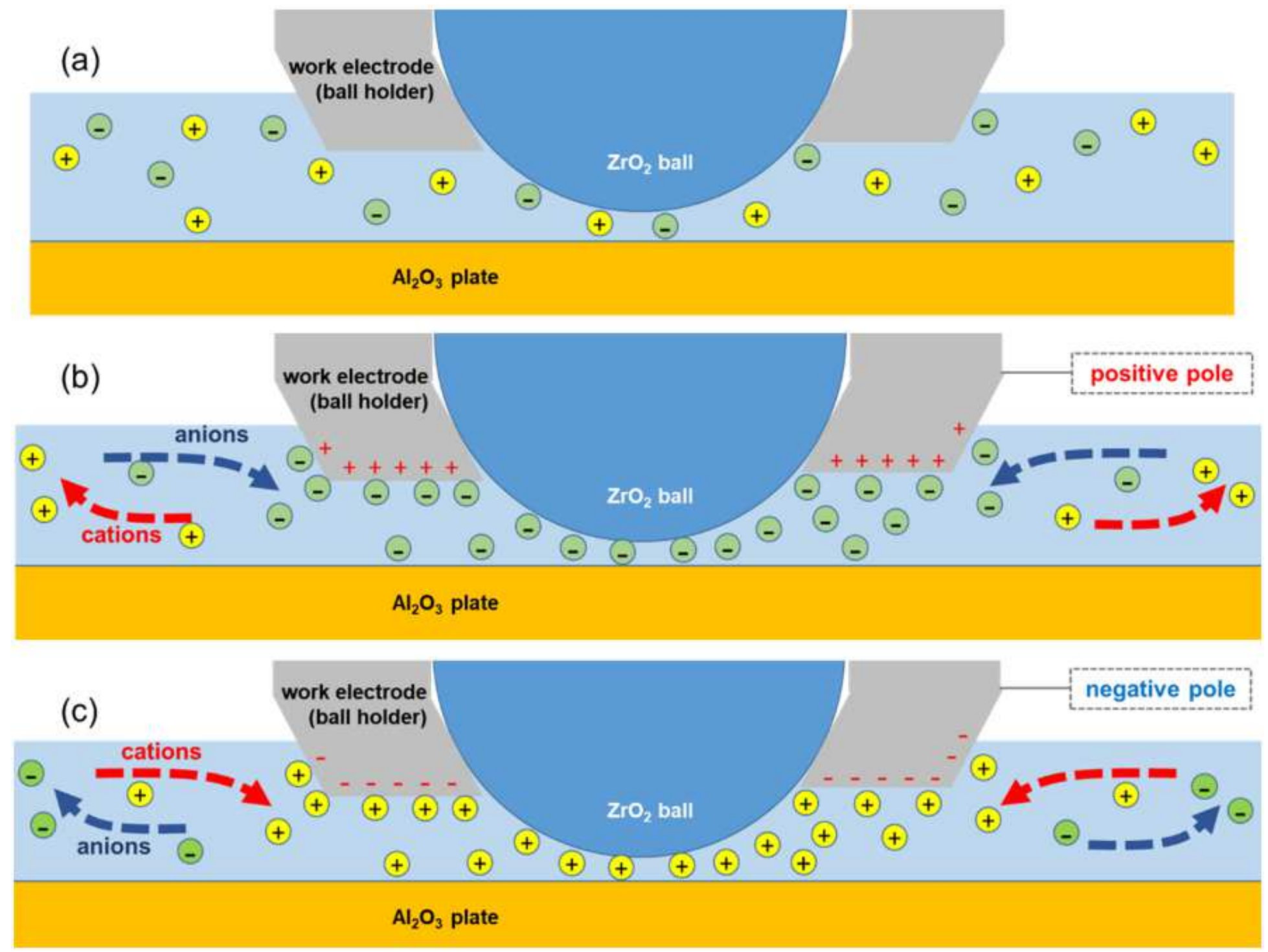

\section{Figure 11}

Schematic illustrations of the active control friction between ceramics. (a) Presence of ions in solution in the absence of applied voltage without consideration of the double electric layer at the solid-liquid interface, (b) anions (such as DS-) accumulate near the contact area when the positive surface potential of the working electrode is applied, and (c) cations (such as $\mathrm{Na}+$ ) accumulate near the contact area when the negative surface potential of the working electrode is applied. 
(a)

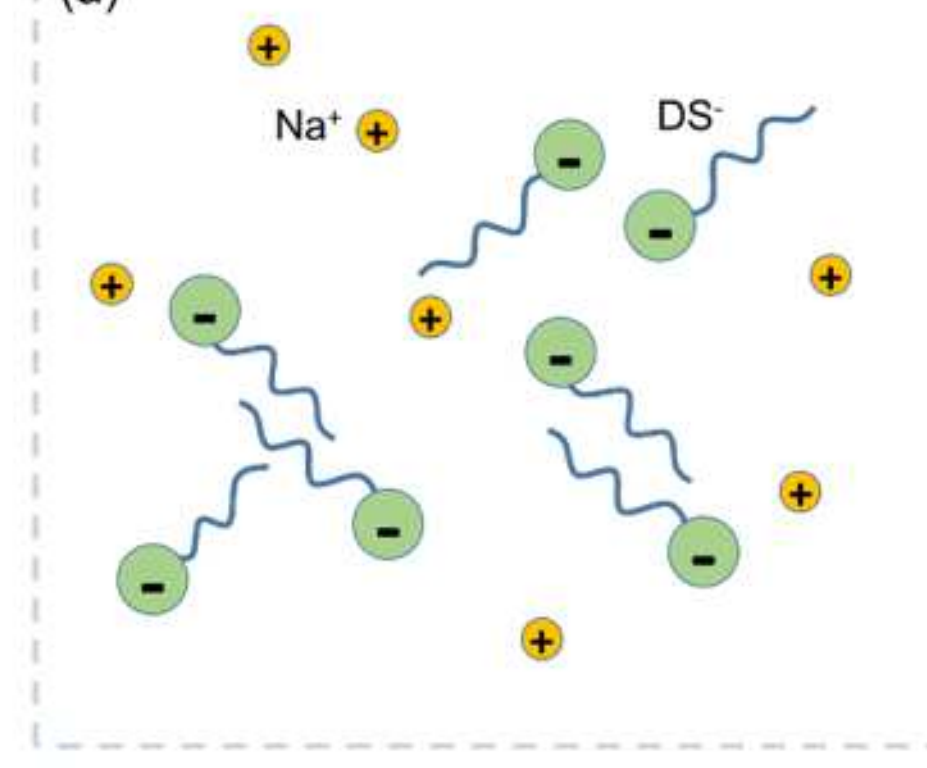

(c)

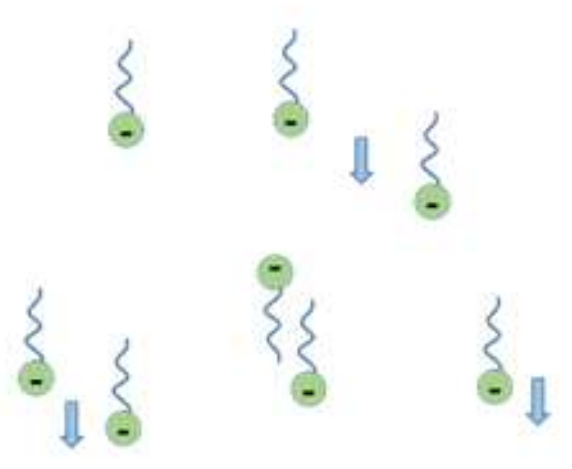

\section{$\mathrm{Al}_{2} \mathrm{O}_{3}$}

(b)

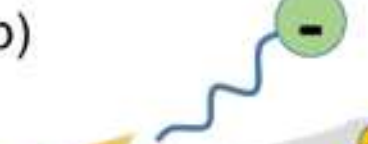

$+\overbrace{}^{-10}+$<smiles>[CH-]</smiles>

slipping plane

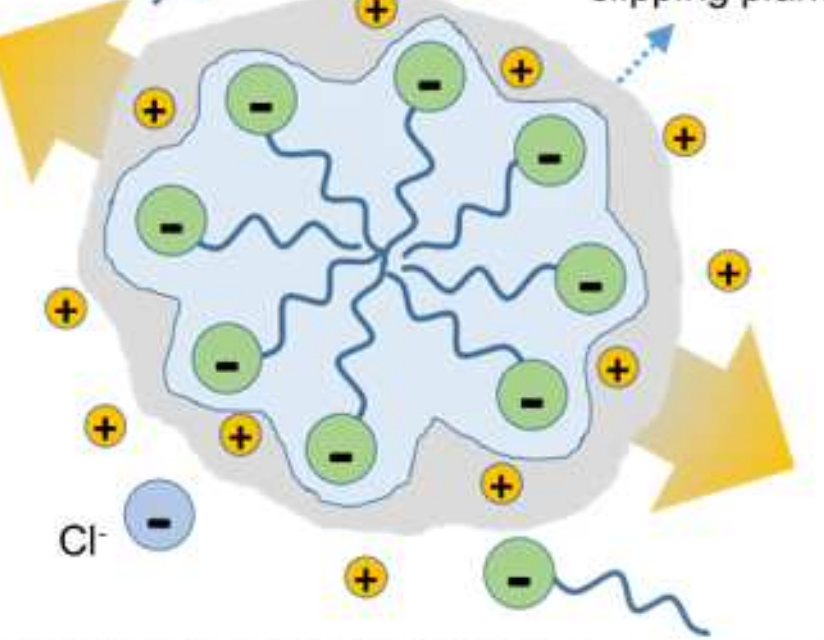

(d)
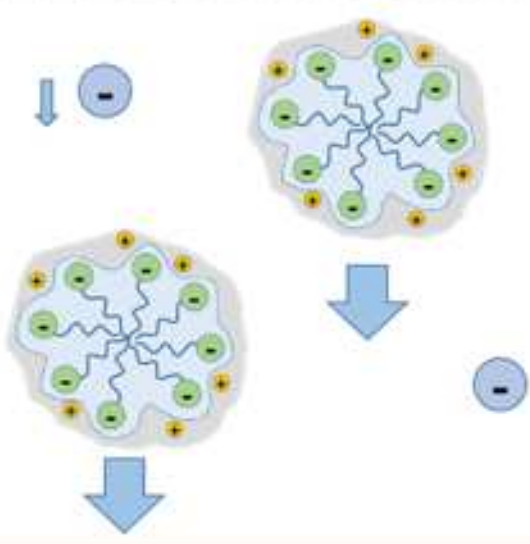

\section{Figure 12}

Schematic diagram of the DS- and $\mathrm{Na}+$ in different conditions. (a) in the bulk phase of $1 \mathrm{mM} \mathrm{SDS}$ solution, (b) in the bulk phase of the mixed solution of $1 \mathrm{mM} \mathrm{SDS}$ and $10 \mathrm{mM} \mathrm{NaCl}$ (c) at the interface of the Al203 solid and $1 \mathrm{mM}$ SDS solution and (d) at the interface of the Al2O3 solid and the mixed solution of $1 \mathrm{mM}$ SDS and $10 \mathrm{mM} \mathrm{NaCl}$. 